\title{
Thermomechanical Behavior of a Thermal Protection System with Different Levels of Damage - Experiments and Simulation
}

\author{
Wei H. Ng ${ }^{*}$, Peretz P. Friedmann ${ }^{\dagger}$, Anthony M. Waas ${ }^{\ddagger}$, and Jack J. McNamara ${ }^{\S}$ \\ Department of Aerospace Engineering \\ University of Michigan \\ Ann Arbor, Michigan 48109-2140 \\ Email: peretzf@umich.edu
}

\begin{abstract}
Experiments are conducted on damaged and undamaged space shuttle tile thermal protection system (TPS) to determine its thermomechnical behavior. The TPS specimens, which consists of a LI-900 tile, the strain isolator pad and the underlying structure, is subjected to a temperature profile corresponding to the thermal loading of the Access to Space (ATS) reference vehicle. Experiments are conducted in a vacuum chamber to allow the ATS re-entry static pressure to be simulated. Temperatures on the top and bottom surfaces of the TPS, as well as the strains in the underlying structure are recorded. The experimental results were used to validate the finite element model. The validated model was then used to account for the interactions of the high speed external flow past a cavity (that represents damage) with the damaged TPS. The modified thermal loads that account for the effects of flow separation and reattachment are indicative of actual flight conditions. Using the improved model, the relative effects of damage on the thermal protection capability and the induced thermal stresses in the TPS are determined by comparing the thermal and structural response of the damaged configurations with the undamaged configuration. Damage increases the thermal loads on the TPS and significantly reduces the radiation heat loss from the surface of the tile, resulting in elevated temperatures. The higher temperatures coupled with the stress concentrations introduced by the damage cause a substantial increase in thermal stresses. Results also indicate that damage can elevate the maximum temperature in the tile to above its melting point.
\end{abstract}

\section{Nomenclature}

$A_{i} \quad=\quad$ Coefficients of bilinear function $F(y, z)$

C $\quad=$ Specific Heat

$D \quad=\quad$ Diameter and depth of damage in TPS

$\mathrm{E} \quad=$ Young's modulus

$F(y, z) \quad=\quad$ Function for varying heat load within damage

$G_{i}, H_{i} \quad=\quad$ Data points of temperature or pressure profiles

$\mathrm{k}=$ Thermal conductivity

$\mathrm{M} \quad=$ Mach number

$n \quad=\quad$ Number of data points used for calculating average difference

* Ph.D. Candidate, Member AIAA

$\dagger$ François-Xavier Bagnoud Professor, Fellow AIAA, AHS

‡ Professor, Associate Fellow, AIAA

$\S$ Postdoctoral Scholar, Member AIAA, currently Assistant Professor of Aerospace Engineering, Ohio State University 


$\begin{array}{ll}\mathrm{P} & =\text { Pressure } \\ \mathrm{q} / \mathrm{q}_{0} & =\text { Heat load ratio of applied thermal loads } \\ \mathrm{T} & =\text { Temperature } \\ \mathrm{T}_{0} & =\text { Stagnation Temperature } \\ u_{i} & =\text { Displacement in the } i \text {-direction } \\ \mathrm{X} & =\text { Distance along base of cavity for Ref.20 and } 21 \\ x, y, z & =\text { Spatial coordinates for FE model } \\ \mathrm{X}_{\mathrm{s}} & =\text { Distance along centerline of damage from upstream-facing lip of damage } \\ \alpha & =\text { Coefficient of thermal expansion (CTE) } \\ v & =\text { Poisson's ratio } \\ \rho & =\text { Density }\end{array}$

\section{Introduction and Problem Statement}

NE of the critical technologies required for spacecrafts and hypersonic vehicles is the thermal protection system (TPS) that protects the vehicle and its payload from the high temperatures generated by aerodynamic heating. While stability at high temperatures is a primary factor in the selection of materials for the TPS, other operational requirements, like cost, weight efficiency, and thermal compatibility with underlying structure, are also major concerns. For reusable launch vehicles (RLV) the TPS has to withstand not only thermal loads, but also mechanical loads as well as harsh chemical environments, repeatedly without failure. The various TPS that have been developed are reviewed in a paper by Scotti, Clay and Rezin ${ }^{1}$, which discusses the structural and material technologies that are currently in use, as well as potential future candidates for TPS in RLV's.

A variety of TPS have been studied analytically and experimentally. Most studies focus on TPS found on NASA's Space Shuttle, which is a first generation reusable spacecraft. Ko and Jenkins ${ }^{2}$ analyzed the Space Shuttle tile using a one-dimensional temperature profile across the tile's thickness. Sawyer ${ }^{3}$ investigated the strains developed in the shuttle tile due to aerodynamic loads and substructure deformations. Experimental verifications of the shuttle tile performance were carried out by Moser and Schneider, ${ }^{4}$ as well as Cooper et. al. ${ }^{5}$ Operational performance of the TPS obtained from flight tests of the shuttle Columbia was evaluated by Ried et. al., ${ }^{6}$ Dotts, Smith and Tillian, ${ }^{7}$ and Neuenschwander, Mcbride and Armour. ${ }^{8}$ Other TPS, not used on the shuttle, have also been considered. Shideler et. al. ${ }^{9}$ performed several analytical and experimental tests on the multiwall TPS. Milos and Squire ${ }^{10}$ conducted a finite element (FE) analysis of the thermal protection system for the X-34 leading edge. Shideler Webb and Pittman ${ }^{11}$ conducted verification tests on newer TPS concepts, which are less fragile than those currently used on the space shuttle. Thermal and structural FE analyses of an advanced metallic TPS were performed by Blosser et. al. ${ }^{12}$

Recently, the authors of this paper examined the effects of damage on the thermomechnical response of the space shuttle tile TPS using the finite element (FE) method. In these studies, ${ }^{13,14}$ the shuttle tile TPS shown in Figure 1, is modeled as a discrete three-layer structure: the LI-900 high temperature reusable surface insulation tile and the strain isolator pad (SIP) attached to the underlying structure. The TPS was assumed to have sustained a "hypervelocity impact"15 type damage, which was approximated as a cylindrical hole ending with a spherical cap as shown in Figure 2. However, the accuracy of the results produced by these models is not known, as they are not validated. In order to increase the confidence in the results, experiments are conducted to verify the FE models.

The FE analyses conducted in the studies ${ }^{13,14}$ assumed that the aerodynamic heating through the damaged region is uniform spatially. However, from Figure 2, it is evident that the heat load profile on the damaged surface of the tile is dependent on the fluid dynamics of a high speed flow past a cavity. The heat load profile on the damaged surface is unlikely to be uniform, and it will differ substantially from the heat load present on the undamaged surfaces. ${ }^{16,17}$ To improve on the thermomechanical analysis, the flow conditions in the damaged region must also be considered.

Therefore, the specific objectives of this study are:

a. Obtain experimental data to validate the FE models, and

b. Determine the heat load on the damaged tile by considering the hypersonic flow past a cavity, and incorporate the refined thermal loading into the thermomechanical analysis in order to determine the effects of damage on TPS response. 
The improved numerical results obtained with the new model, represent a more realistic behavior of the TPS.

\section{Description of Experiments}

The experiments are conducted in the Thermal Structure Testing Laboratory at the Department of Aerospace Engineering of the University of Michigan.

\section{A. Test Facility}

In principle, the laboratory bears a resemblance to facilities at NASA Langley. ${ }^{18}$ The precise re-entry conditions for testing TPS are difficult to duplicate. An alternative is to apply a transient temperature boundary condition that would be attained during re-entry flight to the surface of the TPS test specimen, while simulating re-entry static pressure in a vacuum chamber. Clearly, this facility does not account for the important interactions that are known to exist between high speed flow and vehicle.

An overview of the facility is shown in Figure 3. It consists of the vacuum chamber, pressure control system, radiant heater system, and data acquisition system.

The cylindrical steel vacuum chamber has a diameter of 33.5” and a length of 37”. The chamber is equipped with feed-through for power, gas, and instrumentation for 20 pairs of type $\mathrm{K}$ thermocouples and 12 pairs of strain gages. A vacuum of 40 millitorrs can be achieved when equipped with a $24 \mathrm{cfm}$ dualstage rotary vacuum pump. Nitrogen is bled into the chamber at a controlled rate to simulate re-entry pressures. This is done using the MKS Instruments' type 244/245 control system which includes a control module and a servo-controlled leak valve. The system is a closed-loop feedback system using pressure readings from two capacitance manometers which cover a range of pressure from 1 millitorr to 760 torr.

The radiant heater is a high energy electric infrared heater system manufactured by Innovative Industries, which has also provided a similar unit to NASA. The system uses a quartz lamp radiant heating array capable of rapid changes in heating that is required to simulate transient re-entry temperatures. The 15 " by 16 " heating array can achieve uniform heating on a maximum specimen surface of 12 " by 12 ". The system includes a temperature controller, which allows the user to specify the time-dependent temperature profile during the experiments.

\section{B. Test Specimen and Load Fixture}

The TPS specimen is composed of the LI900 insulation tile, Nomex SIP and aluminum panel, which simulates the underlying structure. The square tile has dimensions of 6.0 " $\times 6.0$ " and a thickness of 2.0 ". It is coated on five sides with reaction-cured glass (RCG) and the uncoated side is bonded to the SIP with RTV-560, which is a room-temperature vulcanizing adhesive. The 0.173 ” thick SIP is also bonded to the square aluminum panel of dimensions $7.5 ” \times 7.5 ” \times 0.063$ ”. The larger aluminum panel is used to allow the use of a load fixture.

The load fixture is made up of two identical square frames with an outer length of 9". The inner window of the frame has a length of 6.2", which is marginally larger than the tile's length of 6.0". The frames are also recessed to allow the aluminum panel to fit snugly. When the specimen and frames are assembled, the underlying structure forms a 0.1 " wide border around the tile and SIP. This is to prevent the fixture from interfering with the thermal expansion of the tile and SIP. The test assembly is shown in Figure 4. The stainless steel fixture has a different coefficient of thermal expansion (CTE) from that of the aluminum panel. When temperature increases, in-plane loads are generated within the aluminum panel due to the mismatched CTEs between the fixture and specimen.

Experiments were conducted with undamaged and damaged specimens with two different damage sizes, $D=1.0$ " or $1.5^{\prime \prime}$.

\section{Instrumentation}

The instrumented specimen and fixture for undamaged and damaged tiles are shown in Figure 5. The undamaged specimen was instrumented with eight type-K Nextel-insulated thermocouples (XC-24-K-30, Omega Engineering) and two high-temperature fully encapsulated Karma-based alloy strain gages (WK13-062AP-350, Vishay Micromeasurements). For specimen with damage, three additional metal-sheathed type-K thermocouples (XL-K-MO-040, Omega Engineering) were used to measure temperatures within the damage. One of the thermocouples, designated Ts, was used for feedback control for the radiant heater system. 


\section{Specimen Assembly}

The assembled specimen and fixture was placed on top of a steel platform that was lined with a 1" thick cerachem blanket, which is an alumina-silica-zirconia fiber based insulation manufactured by Thermal Ceramics. The sides of the specimen were also covered with the cerachem blankets, leaving only the top surface exposed. The platform was placed underneath the radiant heater which is suspended from the ceiling of the vacuum chamber. Photographs and illustration of the assembly are shown in Figure 6.

\section{E. Pressure and Temperature Profiles}

The target re-entry static pressures and temperatures chosen for the experiments were based on the reentry profile of the Access-to-Space (ATS) reference vehicle ${ }^{19}$. The applied surface temperature was calculated based on the surface heating rates of the ATS vehicle. The ATS re-entry pressures and heating rates are shown in Figure 7.

The applied temperatures that would be obtained in the damaged portion of the tile were not known a priori. The damaged surfaces, without the RCG coating, have different surface properties that affect the radiation heat transfer, which is the principal mode of heat transfer in the experiments. The emissivity of the uncoated tile, listed in Table 1, decreases rapidly with temperature, while that for the RCG coating remains relatively constant at 0.85 . Moreover, uniform heating implemented with radiant heater requires that the heated surface should be at a certain distance away from the heat source and this distance should be at four times the bulb spacing. While the undamaged surface are at the required distance from the bulbs, the damaged surfaces are at different distances and orientation to the heater.

\section{Flow Dependent Thermal Loads}

The temperature profiles on damaged TPS obtained in the experiments conducted are quite different to what may be observed in actual re-entry flight. However, if the thermal loads based on actual flight conditions are known, the experimentally validated FE models can be extended to obtain a more accurate prediction of TPS behavior

\section{A. Hypersonic Cavity Flow}

Hypersonic flow past a cavity on the surface of a vehicle is a challenging problem due to complex flow characteristics, such as hypersonic flow separation. ${ }^{16,20}$ Flow separation is important for the heat transfer problem since the aerodynamic heat load varies spatially as the flow passes over the cavity representing damage on the surface of the vehicle. For cavity geometries shown in Figure 8, this flow problem was studied both computationally, ${ }^{17,21}$ and experimentally. ${ }^{16,17,20}$ Cavity flows are typically denoted as either "open" or "closed", depending on certain flow characteristics. In open cavity flows, the external flow passes over the cavity and the separated shear layer re-attaches near the top corner of the upstream-facing wall, thus producing circulation inside the cavity, as shown in Figure 8. Conversely, for closed cavity flows, the separated shear layer re-attaches to the cavity floor upon impingement and then separates again as it approaches the upstream-facing wall. ${ }^{17,20,21}$ The combination between the length to depth ratio of the cavity and the speed of the flow determines whether the cavity flow will be open or closed. Typically, supersonic and hypersonic cavity flows are open if the length to depth ratio of the cavity varies from 1 to 10. Note that the damage considered in this study has a length to depth ratio of 1 , and thus it will produce an open cavity flow.

Two approaches to improve the heat load estimate on a damaged tile are considered in this study. First, the aerothermodynamic flow conditions in the cavity were computed using computational fluid dynamics (CFD) code CFL3D developed by NASA Langley Research Center ${ }^{22}$. This approach is convenient since the computation can be performed for any damage profile considered in the thermomechanical analysis. Two issues that limit the accuracy of the code are the lack of ability to model real gas effects and the limited information of local operating conditions near the damaged tile.

In the second approach, an approximate heat load profile was extracted from results provided in recent studies $^{20,21}$ dealing with the Columbia accident investigation and Space Shuttle Return to Flight Program. The advantage of this approach is that both real gas effects and local flow conditions are captured by this data. Another advantage is the availability of experimental results for validation purposes. The disadvantage is the inability to match the details of the required damage geometry. 


\section{B. Thermal Loads from CFL3D}

The CFL3D code uses an implicit finite-volume algorithm based on upwind-biased spatial differencing to solve the time-dependent Euler and Reynolds-averaged Navier-Stokes equations. Multi-grid and mesh sequencing are available for convergence acceleration. The algorithm, which is based on a cell-centered scheme, uses upwind-differencing based on either flux-vector splitting or flux-difference splitting, and can sharply capture shock waves. This study utilizes the flux-vector splitting scheme.

The grid used to generate aerodynamic heating data for the damaged tile is shown in Figure 9. It consists of $2 \times 433 \times 225$ grid points that extend from 3.5 inches in front of the damaged section to 2.5 inches behind the damaged section, and 4 inches above the tile surface. Note that the damaged portion of the tile considered here consists of a strip having a width of $1 \mathrm{inch}$, and a depth of 1 inch, and it contains $2 \times 151 \times 140$ grid points. This grid geometry implies that only two-dimensional flow past the cavity is considered.

The operating conditions used to generate the aerodynamic heating on the tile are provided in Table 2 . These operating conditions are based on those used in a previous experimental and computational study of hypersonic cavity flows. They were selected since the actual flow conditions on the ATS vehicle are not readily available. These conditions produce laminar flow conditions, and therefore the laminar flow option in CFL3D was implemented. The maximum heat load values for the ATS are assumed to occur during laminar flow conditions, so the use of the laminar flow assumption is appropriate.

Figure 10 depicts the heat load ratio profile obtained from the CFL3D simulation. The heat load ratio is defined as the local heating data (q) normalized by reference heating data $\left(\mathrm{q}_{0}\right)$ obtained from undamaged smooth surface configuration with the same simulation conditions. The results are plotted as a function of a non-dimensional coordinate $\mathrm{X}_{\mathrm{s}} / \mathrm{D}$. According to the definition of $\mathrm{X}_{\mathrm{s}}$, the downstream-facing wall is located between $0<\mathrm{X}_{\mathrm{s}} / \mathrm{D}<0.5$, the "floor" of the cavity is located between $0.5<\mathrm{X}_{\mathrm{s}} / \mathrm{D}<2.07$, and the upstreamfacing wall is located between $2.07<\mathrm{X}_{\mathrm{s}} / \mathrm{D}<2.57$.

Consistent with open cavity flows, ${ }^{16,17,20}$ the heat load ratios within the damage region are generally less than 1.0 except for the portion near the upstream-facing lip of the damage, where the reattachment of the flow occurs. High heat loads are also evident in a region located a small distance downstream of the damaged region.

\section{Thermal Loads from Published Data}

In Refs. 20 and 21, both computational and experimental aerothermodynamic results were generated for hypersonic flows past rectangular cavities. In Ref. 21, CFD was used to predict the hypersonic aerothermodynamic environment for a Shuttle Orbiter with windside tile damage. Furthermore, the computations were performed at the peak heating trajectory point, using the Langley Aerothermodynamic Upwind Relaxation Algorithm (LAURA) code. Note that this code is intended for simulating hypersonic re-entry physics including chemistry. In Ref. 20, results from wind tunnel experiments were generated for cavities and flow conditions similar to those studied in Ref. 21. The experiments were conducted in the Langley 31-inch Mach 10 tunnel. In both cases the cavity length-to-depth ratio was $7.5 .^{20,21}$

Figure 11 depicts heat load ratio profile along the cross section where the maximum heat load ratio is observed within the 3D rectangular cavity based on CFD simulation of the flight conditions. Due to the presence of corners in the cavity geometry, sharp dips in heat load ratios are evident in the profile.

\section{Applied Thermal Loads}

Figure 12 shows the heat load ratio profiles obtained using the two approaches described above. The "uniform" profile shown in the figure corresponds to an approximate upper bound heat load used in our earlier studies. ${ }^{13,14}$ These profiles were used in the current study as scaling factors to multiply the applied surface heat load in order to determine the heat load in the damaged region.

The maximum heat load ratio from the CFL3D results due to flow reattachment at the lip of the upstream-facing wall of the damage, was found to be very large $\left(q / q_{0}=21.5\right)$. Such high peak heat load ratios were not observed in experiments. ${ }^{16,20}$ The maximum heat load ratio for an open cavity observed in the experiments described in Ref. 20 was approximately 4.5; therefore it was decided that the maximum heat load ratio for the profiles used in this study was limited to 4.5 .

The heat load ratio profile based on published data by Everhart et. al. and Pulsonetti et. al. is denoted here as the EP profile. The heat load ratio results along the vertical walls of the cavity were not presented in Refs. 17 and 18. The variation of the profile between $0<\mathrm{X}_{\mathrm{s}} / \mathrm{D}<0.5$ and $2.07<\mathrm{X}_{\mathrm{s}} / \mathrm{D}<2.57$ was obtained by assuming that the results along the vertical walls are similar to those in the CFL3D profile. Thus, the 
sharp dips in heat load ratios in Figure 11 are not present in the EP profile. The maximum heat load ratio was limited again to 4.5 based on the experiments in Ref. 20.

The EP profile is generally more severe than the CFL3D profile; this is probably due to the fact that the cavity length-to-depth ratio for EP profile is much larger than that for the CFL3D profile (7.5 vs 1.0) and it had been noted that heating data in cavities increases with their length-to-depth ratio. The difference may also be due to the use of local flow conditions in the EP profile, compared to freestream conditions used in the CFL3D result. For the EP profile, the flow pass a cavity located on an actual vehicle is used. Before the flow reaches the cavity, it passes through a strong bow shock, thus resulting in a lower Mach number and higher temperatures and pressures when compared to freestream conditions.

\section{Finite Element Analysis}

\section{A. Finite Element Method}

The finite element simulation of the thermomechanical behavior of damaged TPS is based upon the ABAQUS code version $6.4^{23}$ Thermal-mechanical coupling, which represents the conversion of mechanical energy to thermal energy, is neglected when compared to a much larger amount of energy supplied to the system through thermal loading. The thermomechanical response of the system is obtained in two steps. First, the heat transfer problem is solved to obtain the time-dependent temperature distribution in the TPS due to the applied thermal loads and boundary conditions. Subsequently, the thermal stresses caused by the temperature distributions were determined. The solutions were facilitated by using the same mesh for both the heat transfer and thermal stress problems.

In the previous study, stress singularities were detected at the edges and corners of the material interfaces. The presence of geometric and material discontinuities in these regions produces a typical "boundary-layer effect", where the stress gradient changes rapidly. Even with considerable mesh refinement, the meshes used had difficulty producing reliable and converged results. Using the most refined meshes obtainable with the meshing software, converged results from locations sufficiently distant from these stress singularities were computed for the study. Such refined meshes required a very high number of degrees of freedom (dof's), however the accuracy of the solution could not be guaranteed due to the singular nature of the complex boundary stress field.

Tong and Pian ${ }^{24}$ concluded that refining meshes and increasing order of element formulation when using conventional finite elements, is inadequate for producing convergence in elasticity problems with singularities. Therefore the use of extremely fine meshes may not produce an accurate solution. Wang and Yuan ${ }^{25}$ developed a singular composite-edge element which uses stress intensity factors to characterize singular edge stress field. The results in Ref. 25 indicate that stress results using the singular element start to deviate from results based on the conventional element when one is approaching within 5\% (based on specimen length) of the location of the singularity. In the present analysis, the boundary layer effects in the TPS are treated by assuming them to be confined to a region of similar proportions, i.e. 5\%. Using this assumption, a modified portion of the quarter model of the TPS model that is used in this study with the boundary region shaded in grey is depicted in Figure 13. This boundary region is located at the periphery of the TPS, and has a width of $5 \%$ of its length near the interface. Since the computational results are based on conventional elements, results in the shaded region are considered to be unreliable. This implies that the meshes used in this study produce converged results outside this shaded region.

Figure 14 shows the three meshes used in this study. The DC3D10 and C3D10 elements are used for the heat transfer and thermal stress problem, respectively. These are ten-noded quadratic tetrahedron elements, shown in Figure 15. The DC3D10 elements have one temperature degree of freedom per node, and the C3D10 element has three displacement degrees of freedom, $u_{x}, u_{y}$ and $u_{z}$, at each node.

Typically in heat transfer numerical analysis, the lower surface of the underlying structure is assumed to be perfectly insulated. This cannot be achieved in practice, since all insulation conducts and absorbs heat. Therefore, it is more appropriate to use the measured temperature at the lower surface of the insulation as a boundary condition. The mesh in Figure 14(a), consists of the tile, SIP, aluminum panel, fixture and portion of the cerachem insulation, is used for correlating the temperature results obtained in experiments. Due to symmetry, the experiment can be represented by a quarter model of the TPS

The mesh in Figure 14(b) is used for correlating the strain results. In this mesh, the cerachem insulation is not included because it is flexible and thus, is assumed to no effect on the stresses and strains in the system. For this analysis, the measured temperature at the lower surface of the underlying structure was used as the applied boundary condition to produce more accurate results. 
Once the FE model used is validated, it can be extended to include flow-dependent heat loads. The mesh used for the extended analysis is shown in Figure 14(c). A half-model is required in order to capture the effects of the flow.

\section{B. Heat Transfer Analysis}

For the analysis correlating the experimental results, measured temperatures from experiments are applied as boundary conditions at the nodes on the top and bottom surfaces of the meshes, as well as the nodes on the damaged surfaces. All side surfaces are assumed to be perfectly insulated.

For the extended analysis, heat flux boundary conditions are applied on the top surface of the mesh. The boundary conditions are based on the transient aerodynamic surface heat load re-entry profile of the ATS reference vehicle, as shown in Figure 7. The sides and the inner surface of the TPS are assumed to be perfectly insulated, which corresponds to a worst-case scenario. While this profile is appropriate for the undamaged portions of the tile, special consideration is required in the damaged region.

To apply the flow dependent heat loads, the tile surface is divided into several sections as shown in Figure 16. On the undamaged surface, colored in green, a small region right after the damage is separated to allow elevated heat loads to be applied. Within the damage, the surface was divided into two sections: the downstream-facing section, colored light blue, and the upstream-facing section, colored blue. These two sections are further divided into sub-sections so that reasonable linear or polynomial curve fits can be obtained for the heat load ratio profiles shown in Figure 12.

The curve fits for the heat load ratio profiles are obtained as functions of $y$ only, i.e. the heat load ratio varies only with the depth of the damage. In order to have a three-dimensional variation of the heat load ratio, the curve fits for each subsection are multiplied by a bilinear function of $y$ and $z$ of the form:

$$
F(y, z)=A_{1} y+A_{2} y z+A_{3} z+A_{4}
$$

To determine the coefficients, $A_{1}-A_{4}$, for each subsection, the following assumptions are made:

i. Along the centerline of the damage (red dotted line in Figure 16), the heat load ratio profile is the same as that in Figure 12.

ii. At the outer edge of the damage, the heat load ratio is equal to 1.0, since the tangent of the edge is parallel to the flow.

iii. Along the yellow dotted line in Figure 16, the heat load ratio at the corners of each subsection is the average of the centerline heat load ratios from the upstream and downstream-facing sections.

Figure 17(a) shows the heat load ratios from the EP profile at the corners of each sub-section within the damage. The exact values from the EP profile are in bold type, while the values based on the assumptions above are in regular type.

Figure 17(b) shows the values that Eq. (1) has to satisfy in order to obtain the required heat load ratios at each corner of the subsections from the curve fits. Using these values, the coefficients, $A_{1}-A_{4}$, for each subsection can be calculated. Essentially, Eq. (1) preserves the EP profile along the centerline of the damage while allowing it to vary linearly with respect to $z$ to the required values at the corners of each subsection.

The primary mechanism of heat loss in the TPS is radiation from the top surface of the tile. Convection heat loss is disregarded. On the undamaged surface, all radiated heat is lost to open space. However, in the damaged region, some of the heat radiated from the damaged surface is intercepted by other surfaces, as shown schematically in Figure 18, resulting in lower net heat loss to space. This cavity radiation in the damaged region is accounted for in the analysis by using the keyword commands *CAVITY DEFINITION and $*$ RADIATION VIEWFACTOR in ABAQUS, which determines the heat exchange between element surfaces within the damaged region. The TPS is assumed to be exposed to the ATS pressure profile.

The unsteady heat transfer problem is solved in the time domain by using a carefully selected time-step so as to ensure convergence of the transient solution. This correct time-step is determined by repeatedly solving the heat transfer problem with decreasing time-steps. When the difference in the temperature results between two consecutive time-steps is less than $1.0 \%$, the solution is considered to be converged.

New nodal temperatures are computed at each time-step based on the time-dependent thermal loading conditions as well as the temperature distribution obtained from the previous time step. The nodal temperatures at each time step are stored for subsequent use by the thermal stress analysis. 


\section{Thermal Stress Analysis}

The schematic description of boundary conditions used in the analysis is provided in Figure 19. For the analysis correlating experiments, the unrestrained boundary condition, BC1, was used. The restrained boundary condition, $\mathrm{BC} 2$, was used in the extended analysis incorporating flow dependent heat loads. The boundary condition was applied only to the underlying structure since the tile and SIP are attached to the underlying structure in such a manner that they are not load bearing elements. Symmetric boundary conditions are applied to nodes lying on the plane of symmetry. The displacements and stresses at each time-step were computed using the time-dependent nodal temperatures from the heat transfer solution.

\section{Results and Discussion}

The results are presented in two sections; first, the experimental results used to validate the FE model are discussed. These results also show the performance of the facility for testing damaged TPS. In the second section, numerical results from the extended FE simulation that includes flow dependent heat loads are presented.

\section{A. Experimental Results}

The measured pressures during experiment are compared with the target re-entry pressure profile as shown in Figure 20. Due to the limitations of the pressure control system, there are considerable differences between the measured and target profiles for the first 500 seconds. Subsequently, the average difference between measured and target pressure is less than $2 \%$. The average difference is defined as

$$
\frac{1}{n} \sum_{i=1}^{n}\left|\frac{G_{i}-H_{i}}{H_{i}}\right| \times 100 \%
$$

where $G_{i}$ and $H_{i}$ are data points of the profiles being compared and $n$ is number of data points.

Figure 21 shows the temperatures measured on the top surface at three different locations on the specimen as well as the target re-entry temperature profile. Using the center thermocouple, T1 in Figure 5, for comparison, the measured temperature matches the target temperatures quite well, with an average difference of $2.2 \%$ in the initial 2000 seconds. Beyond that, the rapid drop in target temperature cannot be simulated without active cooling, a feature that is not available in the current test facility. From Figure 21, it is evident that the temperature uniformity on specimen surface is very good up to about 3000 seconds. Subsequently, temperatures at the edge of the specimen diverge from those at the center.

The measured temperatures within the damaged region of specimen with $D=1.5$ ”, TD1, TD2 and TD3, are shown in Figure 22. These temperatures are quite similar to the surface temperatures, and the variations between the three measured temperatures are relatively small, with a standard deviation of less than $14^{\circ} \mathrm{C}$ after the initial 500 seconds. Figure 23 shows the measured temperature, TD3, at the base of the damaged region for damaged specimen with $D=1.0$ " and 1.5". The variation in size of the damaged region did not seem to have a large effect on these temperatures, since the average difference is only $3 \%$,. These results indicate the limitations of testing damaged TPS in such a facility, since elevated temperatures within damaged region and variations in applied temperatures with respect to damage size cannot be obtained.

Based on the experimental results, the assumption that the applied temperatures on the undamaged and damaged surfaces are uniform is used. Also, the measured temperatures from the "center" thermocouple (T1 in Figure 5) and the average temperature of the three thermocouples within the damaged region, TD1, TD2 and TD3, are used as boundary conditions in the FE analysis.

The material properties used in the model are obtained from a couple of sources. ${ }^{26,27}$ The density, specific heat, thermal conductivity, Young's modulus, Poisson's ratio, and coefficient of thermal expansion used in the analyses for the aluminum underlying structure are given in Table 3 . The conductivity of the SIP as a function of pressure and temperature is given in Table 4 and its other material properties are shown in Table 5. The conductivity of the LI-900 tile as a function of pressure and temperature can be found in

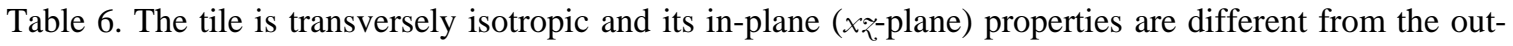
of-plane ( $y$-direction) properties. The first value listed is the in-plane conductivity while the value in parentheses is the out-of-plane conductivity. Other material properties of the tile are given in Table 7.

The measured temperature at the center of the underlying structure, T10 in Figure 5, is used for validation purposes. The measured temperature and predicted temperature from $\mathrm{FE}$ analysis are shown in Figure 24. Since the differences in results for the undamaged and damaged configuration with $D=1.0$ " for both experiments and FE analysis are less than $2.0 \%$, the $D=1.0$ " results are not plotted. While the 
presence of damage allows the surface temperatures to be applied closer to the underlying structure, the damaged size considered combined with the applied temperature load that can be achieved in the test facility results only in modest increase in heat retained within the system. Thus, the changes in temperatures within the structure due to damage are not significant. However, the FE models are able to predict the measured temperatures well, with an average difference of $4.3 \%$ and $3.0 \%$ for the undamaged and damaged configuration with $D=1.5$ ” respectively. When predicting peak temperatures, the differences are even smaller at $0.5 \%$ and $0.9 \%$.

Figure 25 shows the predicted and measured strain results for the undamaged and damaged $(D=1.5$ ”) configuration. The FE models were found to produce relatively good results, with an average difference of $7.5 \%$ and $5.0 \%$ for the undamaged and damaged configurations respectively. The predictions of the peak strain results are even better with a difference of $0.32 \%$ and $2.7 \%$.

These results indicate that the FE model is in good agreement with the experiments and thus the FE analysis is validated by comparison with experimental results.

\section{B. Thermomechanical behavior of TPS subjected to flow dependent heat loads}

The maximum temperatures and von Mises stresses that occur in the tile, SIP and underlying structure, including the times when they occur are shown in Tables 17 and 18 respectively. Two values are provided for each damaged configuration: one for the CFL3D thermal loading case provided in bold type in left column and the other for the EP thermal loading case, italicized in right column. The percentage changes in the maximum temperatures and von Mises stresses for the damaged configurations compared to the undamaged, baseline configuration are also provided in the tables.

The flow dependent heat loads (CFL3D and EP) are generally of lower magnitude than the surface heat load except for two regions: a very small region at the upper lip of the downstream-facing section and a larger region on the upper lip of the upstream-facing section. In these regions, the peak heat load for both flow dependent heat profiles are larger than the surface heat load by a factor of 4.5. In previous studies, ${ }^{13,14}$ it was determined that when subjected to the "uniform" heat load, cavity radiation and the reduction in emissivity due to the loss of the RCG coating resulted in very high temperatures within the damage. Thus, it is not unreasonable to assume that the large spike in heat load due to flow reattachment would generate much higher maximum temperatures in the tile. However, the maximum temperatures in the tile due to flow dependent heat loads are similar in magnitudes to those obtained from the "uniform" heat load with the CFL3D heat load producing results that are less than 7\% lower and the EP heat load producing results less than $9 \%$ higher. There are several explanations for this behavior. First, at such high temperatures, heat loss by radiation is so efficient $\left(\propto \mathrm{T}^{4}\right)$ that even with a large increase in heat load, the increase in temperatures are relatively modest. Second, the uniform heat profile, where all surfaces within the damaged region are subjected to the same heat load as the surface, is actually quite severe. Third, for the flow dependent heat profiles, other than the two small areas which experience higher heat loads, much of the surfaces within the damaged region are subjected to substantially lower heat loads when compared to the "uniform" profile. Figure 26 illustrates the temperature contour plot of the damaged configuration, with $D$ $=1.0$ ", subjected to EP heat load when the maximum temperature in the tile is attained. The non-uniformity of the heat load, coupled with cavity radiation, results in a complex distribution of temperatures within the damaged region. Even though much of the heat load within the damaged region is lower than the surface heat load, the effects of cavity radiation retained substantial heat to elevate the temperatures to above surface temperatures. It is also interesting to note that similar elevated heat load on the undamaged surface downstream of the damaged region, where there is neither cavity radiation nor reduction in emissivity, produces maximum temperatures that are significantly lower than those within the damaged region.

For the tile, the smallest damage considered with the CFL3D heat load increases the maximum temperature by $73.6 \%$ to $1703{ }^{\circ} \mathrm{C}$ which is slightly lower than the melting point of the tile $\left(1704{ }^{\circ} \mathrm{C}\right)$. In all other cases, the melting temperature of the tile was exceeded. For the largest damage size, the EP heat load increases the maximum temperature to $2313{ }^{\circ} \mathrm{C}$, which represents a massive increase of $135.8 \%$. However, it should be noted that the EP profile was for a cavity that has a much larger length-to-depth ratio than the CFL3D results. Temperatures in the SIP and underlying structure are also increased significantly, by up to $101 \%$. However, the results indicate that the imposed limit temperature of the underlying structure (150 ${ }^{\circ} \mathrm{C}$ ) is exceeded while the vehicle is still in flight ( $<3000$ seconds) only for the $D=1.5$ ” cases. However, it should be noted that no heat loss through the inner surface and sides of the system was assumed, which is a very conservative assumption. 
The thermal stress results are obtained disregarding the melting temperature of the tile. The presence of damage increases the maximum von Mises stresses in the tile substantially. The smallest damage size considered increases the maximum stresses by more than $30 \%$. The large increase in stresses is a result of the stress concentration due to damage as well as the severe thermal gradients generated by the flow dependent heat loads. For the cases based on CFL3D, maximum stresses in the tile decrease with damage size. With the EP heat load, no discernible trends were observed. The failure strength of the tile was not exceeded in all cases.

The maximum stresses for both the SIP and structure increase with increasing damage size. For both SIP and underlying structure, the maximum stresses were found to be above the failure strength of the material when $D=1.5$ " with both heat loads. However, this should be viewed in light of the fact that conservative boundary conditions had been used.

While the damage sizes considered are unlikely to adversely affect the underlying structure and SIP during flight, the exceeded melting point of the tile is a concern. The tile is not a load-bearing structure, thus damage growth need not necessarily lead to catastrophic failure. As the maximum temperature occurs at the upper lip of the damaged region, damage progression will likely "open up" the cavity and alleviate the effects of cavity radiation. However, the nature of the flow and heat load will also be changed.

\section{Concluding Remarks}

Experiments using radiant heaters were conducted on a TPS used on the Space Shuttle. Results from the experiment illustrate the limitations of testing damaged TPS under radiant heating. The current test facility is incapable of producing non-uniform temperature distribution and elevated temperatures within the damaged region. The differences in experimental results due to damage were relatively small. However, these results allow the validation of FE simulation model, which can be extended to provide a numerical simulation incorporating heat loads based on interaction between flow and damaged TPS that correspond to flight conditions. The extended FE simulation indicates that flow dependent heat loads combined with a modest damage size of 0.5 " is capable of elevating the maximum temperature in the tile beyond its melting point.

The TPS is a critical component of space transport systems and failure can have catastrophic consequences. Thus, understanding the effects of damage on the TPS is of fundamental importance. The results presented provide valuable insight into modelling the damage tolerance of TPS. They illustrate the significance of conducting the tests in an arc jet hypersonic tunnel that can represent the interactions between flow and damaged TPS, without which TPS test have only very limited value.

\section{Acknowledgments}

This work was supported by the Space Vehicle Technology Institute under grant NCC3-989 jointly funded by NASA and DOD within the NASA Constellation University Institutes Project, with Claudia Meyer as the project manager. We would also like to thank Sandra Tetley, Mark Dub and Cooper Snapp for their help in securing materials for the experiments.

\section{References}

1 Scotti, S.J., Clay, C. and Rezin, M., "Structures and Materials Technologies for Extreme Environments Applied to Reusable Launch Vehicles". AIAA/ICAS International Symposium and Exposition, AIAA Paper 2003-2697, Dayton, OH, Jul. 2003.

2 Ko, W.L. and Jenkins, J.M., "Thermal Stress Analysis of Space Shuttle Orbiter Wing Skin Panel and Thermal Protection System”, NASA Technical Memorandum 88276.

3 Sawyer, J.W., "Effect of Strain Isolator Pad on Inplane Strain in Shuttle Orbiter Thermal Protection System Tiles", NASA Technical Paper 2141.

4 Moser, T.L. and Schineider, W.C., "Strength Integrity of the Space Shuttle Orbiter Tiles", AIAA-812469, $1^{\text {st }}$ Flight Testing Conference, Las Vegas, NV, NOV. 1981.

5 Cooper, P.A., Miserentino, R., Sawyer, J.W. and Leatherwood, J.D., "Effect of Simulated Mission Loads on Orbiter Thermal Protection System Undensified Tiles", Journal of Spacecraft and Rockets, Vol. 21, No. 5. Sep-Oct 1984

6 Ried, T.C., Goodrich, W.D., Li, C.P., Scott, C.D., Derry, S.M. and Maraia, R.J., "Space Shuttle Orbiter 
Entry Heating and TPS Response: STS-1 Predictions and Flight Data”, NASA Conference Publication 2216, Pg. 327-347, 1982

7 Dotts, R.L., Smith, J.A. and Tillian, D.J., "Space Shuttle Orbiter Reusable Surface Insulation Flight Results”, NASA Conference Publication 2283, Part 2, Pg. 949-966, 1983.

8 Neuenschwander, W.E., McBride, D.U. and Armour, G.A., "Shuttle TPS Thermal Performance and Analysis Methodology”, NASA Conference Publication 2283, Part 2, Pg. 1025-1064, 1983.

9 Shideler, J.L., Kelly, H.N., Avery, D.E., Blosser, M.L. and Adelman, H.M., "Multiwall TPS - An Emerging Concept”, Journal of Spacecraft and Rockets, Vol. 19, No. 4, Jul-Aug 1982.

10 Frank S. Milos and Thomas H. Squire, "Thermostructural Analysis of X-34 Wing Leading-Edge Tile Thermal Protection System”, Journal of Spacecraft and Rockets, Vol. 36, No. 2, Mar-Apr 1999.

11 Shideler, J.L., Webb, G.L. and Pittman, C.M., "Verification Tests of Durable Thermal Protection System Concepts”, Journal of Spacecraft and Rockets, Vol. 22, No. 6, Nov-Dec 1985.

12 Blosser, M.L., Chen, R.R., Schmidt, I.H., Dorsey, J.T., Poteet, C.C. and Bird, R.K., "Advanced Metallic Thermal Protection System Development”, AIAA $40^{\text {th }}$ Aerospace Sciences Meeting \& Exhibit, AIAA Paper 2002-0504, Reno, NV, Jan. 2002

13 Ng, W.H., Friedmann, P.P, Waas, A.M., "Thermomechanical Analysis of a Damaged Thermal Protection System”, AIAA Paper No. 2005-2301, 46 ${ }^{\text {th }}$ AIAA/ASME/ASCE/AHS/ASC Structures, Structural Dynamics, and Materials Conference, Austin TX, Apr 2005

14 Ng, W.H., Friedmann, P.P and Waas, A.M., "Thermomechanical Analysis of a Thermal Protection System with Defects and Heat Shorts”, AIAA Paper No. 2006-2212, $47^{\text {th }}$ AIAA/ASME/ASCE/AHS/ASC Structures, Structural Dynamics, and Materials Conference, Newport RI, May 2006

15 Christiansen, E.L. and Friesen, L., "Penetration Equations for Thermal Protection Material", International Journal Impact Engineering, Vol. 20, Pg. 153-164, 1997

16 Nestler, D.E., Saydah, A.R. and Auxer, W.L., "Heat Transfer to Steps and Cavities in Hypersonic Turbulent Flow", AIAA Paper No. 68-673, AIAA Fluid and Plasma Dynamics Conference, Los Angeles CA, Jun 1968

17 Soltani, S. and Hillier R., “An Experimental and Computational Study of Hypersonic Cavity Flows”, AIAA paper No. 94-0766, 32 ${ }^{\text {nd }}$ Aerospace Sciences Meeting and Exhibit, Reno NV, Jan 1994

18 Daryabeigi, K., Knutson, J.R. \& Sikora, J.G., "Thermal Vacuum Facility for Testing Thermal Protection Systems,” NASA Technical Memorandum 2002-211734, June 2002.

19 Myers, D.E., Martin, C.J. and Blosser, M.L., "Parametric Weight Comparison of Advanced Metallic, Ceramic Tile, and Ceramic Blanket Thermal Protection Systems”, NASA TM-2000-210289, 2000

20 Everhart, J.L., Alter, S.J., Merski, N. R., Wood, W. A., and Prabhu, R.K., "Pressure Gradient Effects on Hypersonic Cavity Flow Heating," AIAA Paper No. 2006-185, 44 $4^{\text {th }}$ Aerospace Sciences Meeting \& Exhibit, January 2006.

21 Pulsonetti, M. V., and Wood, W., "Computational Aerothermodynamic Assessment of Space Shuttle Orbiter Tile Damage - Open Cavities," AIAA Paper No. 2005-4679, $38^{\text {th }}$ AIAA Thermophysics Conference, June 2005.

22 Krist, S.L., Biedron, R.T. and Runsey, C.L., “CFL3D User’s Manual” (Version 5.0), NASA, RM 1998-208444, 1997

23 “ABAQUS/Standard User’s Manual Version 6.4,” Hibbitt, Karlsson \& Sorensen, Inc., Pawtucket, RI.

24 Tong, P., and Pian, T.H.H., "On Convergence of the Finite Element Methods for Problems with Singularity,” International Journal of Solids and Structures, Vol. 9, Pg. 313-321, 1973

25 Wang, S.S., and Yuan, F.K., "A Singular Hybrid Finite Element Analysis of Boundary-Layer Stresses in Composite Laminates,” International Journal of Solids and Structures, Vol. 19, No. 9 Pg. 825-837, 1983

26 Thermal Protection Systems Expert (TPSX) Material Properties Database V4, tpsx.arc.nasa.gov

27 Sawyer, J.W., "Mechanical Properties of the Shuttle Orbiter Thermal Protection System Strain Isolator Pad," Journal of Spacecraft and Rockets, Vol. 21, No. 3, May-Jun 1984 


\begin{tabular}{|c||c||}
\hline Temperature $\left({ }^{\circ} \mathbf{C}\right)$ & Emissivity of Uncoated LI-900 Tile \\
\hline 27 & 0.88050 \\
\hline 127 & 0.83613 \\
\hline 227 & 0.76578 \\
\hline 327 & 0.68410 \\
\hline 427 & 0.60390 \\
\hline 527 & 0.53177 \\
\hline 627 & 0.46981 \\
\hline 727 & 0.41785 \\
\hline 827 & 0.37477 \\
\hline 927 & 0.33918 \\
\hline 1027 & 0.30980 \\
\hline 1127 & 0.28548 \\
\hline 1227 & 0.26527 \\
\hline 1327 & 0.24841 \\
\hline
\end{tabular}

Table 1. Emissivity of uncoated tile with respect to temperature

\begin{tabular}{|l|c|}
\hline Mach Number (M) & 8.1 \\
\hline Reynold's Number (Re) & $1.0 \times 10^{6}$ \\
\hline Stagnation Temperature $\left.\mathbf{( T}_{\mathbf{0}}\right)$ & $1050 \mathrm{~K}$ \\
\hline \hline
\end{tabular}

Table 2. Operating conditions used to study the cavity flow of a damaged TPS

\begin{tabular}{|c||c||c||c||c||}
\hline $\begin{array}{c}\mathbf{T} \\
\left({ }^{\circ} \mathbf{C}\right)\end{array}$ & $\begin{array}{c}\mathbf{C} \\
\left(\mathbf{J} / \mathbf{k g}{ }^{\circ} \mathbf{C}\right)\end{array}$ & $\begin{array}{c}\mathbf{k} \\
\left(\mathbf{W} / \mathbf{m}{ }^{\circ} \mathbf{C}\right)\end{array}$ & $\begin{array}{c}\mathbf{E} \\
(\mathbf{G P a})\end{array}$ & $\begin{array}{c}\boldsymbol{\alpha} \\
\left(\mathbf{1 0}^{-6} /{ }^{\circ} \mathbf{C}\right)\end{array}$ \\
\hline-73.2 & 787.0 & 163.0 & - & - \\
\hline-17.8 & - & - & - & 21.9 \\
\hline 21.0 & - & - & 72.4 & - \\
\hline 26.9 & 875.0 & 177.0 & - & - \\
\hline 37.8 & - & - & 72.0 & 22.6 \\
\hline 93.3 & - & - & 70.4 & 23.2 \\
\hline 126.9 & 925.0 & 186.0 & - & - \\
\hline 148.9 & - & - & 68.5 & 23.6 \\
\hline 204.4 & - & - & 64.3 & 24.0 \\
\hline 260.0 & - & - & 57.3 & 24.4 \\
\hline 315.6 & - & - & 50.5 & 24.9 \\
\hline 326.9 & 1042.0 & - & - & - \\
\hline 371.1 & - & - & - & 25.4 \\
\hline 426.7 & - & - & - & 26.0 \\
\hline 482.2 & - & - & - & 26.7 \\
\hline
\end{tabular}

Table 3. Material properties of the underlying structure (Aluminum 2024) 


\begin{tabular}{||c||c|c|c|c|c||}
\cline { 2 - 6 } \multicolumn{1}{c|}{} & \multicolumn{5}{c|}{$\mathbf{P}(\mathbf{P a})$} \\
\hline \hline $\mathbf{T ~}\left({ }^{\circ} \mathbf{C}\right)$ & 10.133 & 101.33 & 1013.3 & 10133 & 101330 \\
\hline \hline-17.6 & 0.009173 & 0.01904 & 0.03081 & 0.03427 & 0.03548 \\
\hline 38.0 & 0.009865 & 0.02146 & 0.03600 & 0.04067 & 0.04223 \\
\hline 93.5 & 0.01090 & 0.02337 & 0.04154 & 0.04725 & 0.04933 \\
\hline 149.1 & 0.01263 & 0.02631 & 0.04708 & 0.05504 & 0.05711 \\
\hline 204.6 & 0.01575 & 0.02908 & 0.05244 & 0.06421 & 0.06611 \\
\hline 315.7 & 0.02077 & 0.03548 & 0.06750 & 0.08308 & 0.08533 \\
\hline 426.9 & 0.02700 & 0.04327 & 0.08654 & 0.1052 & 0.1073 \\
\hline
\end{tabular}

Table 4 . Conductivity of SIP $\left(\mathrm{W} / \mathrm{m}^{-}{ }^{\circ} \mathrm{C}\right)$ with respect to temperature and pressure

\begin{tabular}{||c||c||}
\hline $\begin{array}{c}\mathbf{T} \\
\left({ }^{\circ} \mathbf{C}\right)\end{array}$ & $\begin{array}{c}\mathbf{C} \\
\left(\mathbf{J} / \mathbf{k g}^{\circ} \mathbf{C}\right)\end{array}$ \\
\hline-17.6 & 1306.3 \\
\hline 93.5 & 1339.8 \\
\hline 204.6 & 1402.6 \\
\hline 615.7 & 1444.5 \\
\hline
\end{tabular}

$$
\begin{aligned}
& \boldsymbol{\rho}=194 \mathrm{~kg} / \mathrm{m}^{3} \\
& \mathbf{E}=30 \mathrm{kPa} \\
& \boldsymbol{v}=0.3 \\
& \boldsymbol{\alpha}=18 \times 10^{-6} /{ }^{\circ} \mathrm{C}
\end{aligned}
$$

\begin{tabular}{|c|c|c|c|c|c|}
\hline & \multicolumn{5}{|c|}{$\mathbf{P}(\mathbf{P a})$} \\
\hline $\mathrm{T}\left({ }^{\circ} \mathrm{C}\right)$ & 10.133 & 101.33 & 1013.3 & 10133 & 101330 \\
\hline-17.6 & $\begin{array}{c}0.02597 \\
(0.01298)\end{array}$ & $\begin{array}{c}0.03116 \\
(0.01731)\end{array}$ & $\begin{array}{c}0.04847 \\
(0.03168)\end{array}$ & $\begin{array}{c}0.05712 \\
(0.04328)\end{array}$ & $\begin{array}{c}0.06751 \\
(0.04760)\end{array}$ \\
\hline 121.3 & $\begin{array}{c}0.03462 \\
(0.01593)\end{array}$ & $\begin{array}{c}0.03981 \\
(0.02164)\end{array}$ & $\begin{array}{c}0.05712 \\
(0.03895)\end{array}$ & $\begin{array}{c}0.07097 \\
(0.05470)\end{array}$ & $\begin{array}{c}0.08136 \\
(0.05903)\end{array}$ \\
\hline 260.2 & $\begin{array}{c}0.04501 \\
(0.02164)\end{array}$ & $\begin{array}{c}0.05193 \\
(0.02891)\end{array}$ & $\begin{array}{c}0.07270 \\
(0.04778)\end{array}$ & $\begin{array}{c}0.08828 \\
(0.06924)\end{array}$ & $\begin{array}{c}0.09867 \\
(0.07495)\end{array}$ \\
\hline 399.1 & $\begin{array}{c}0.06059 \\
(0.03029)\end{array}$ & $\begin{array}{l}0.06924 \\
(0.3739)\end{array}$ & $\begin{array}{c}0.08828 \\
(0.05626)\end{array}$ & $\begin{array}{c}0.1108 \\
(0.08517)\end{array}$ & $\begin{array}{c}0.1212 \\
(0.09244)\end{array}$ \\
\hline 538.0 & $\begin{array}{c}0.08482 \\
(0.04033)\end{array}$ & $\begin{array}{c}0.09001 \\
(0.04760)\end{array}$ & $\begin{array}{c}0.1091 \\
(0.06786)\end{array}$ & $\begin{array}{c}0.1402 \\
(0.1039)\end{array}$ & $\begin{array}{c}0.1523 \\
(0.1139)\end{array}$ \\
\hline 676.9 & $\begin{array}{c}0.1142 \\
(0.05331)\end{array}$ & $\begin{array}{c}0.1229 \\
(0.06059)\end{array}$ & $\begin{array}{c}0.1437 \\
(0.08517)\end{array}$ & $\begin{array}{c}0.1800 \\
(0.1255)\end{array}$ & $\begin{array}{c}0.1921 \\
(0.1354)\end{array}$ \\
\hline 815.7 & $\begin{array}{c}0.1541 \\
(0.07201)\end{array}$ & $\begin{array}{c}0.1662 \\
(0.07945)\end{array}$ & $\begin{array}{c}0.1887 \\
(0.1068)\end{array}$ & $\begin{array}{c}0.2285 \\
(0.1515)\end{array}$ & $\begin{array}{c}0.2423 \\
(0.1631)\end{array}$ \\
\hline 954.6 & $\begin{array}{c}0.2060 \\
(0.09815)\end{array}$ & $\begin{array}{c}0.2164 \\
(0.1056)\end{array}$ & $\begin{array}{c}0.2423 \\
(0.1328)\end{array}$ & $\begin{array}{c}0.2891 \\
(0.1835)\end{array}$ & $\begin{array}{c}0.3029 \\
(0.1956)\end{array}$ \\
\hline 1093.5 & $\begin{array}{c}0.2648 \\
(0.1271)\end{array}$ & $\begin{array}{c}0.2804 \\
(0.1354)\end{array}$ & $\begin{array}{c}0.3116 \\
(0.1631)\end{array}$ & $\begin{array}{c}0.3670 \\
(0.2198)\end{array}$ & $\begin{array}{c}0.3826 \\
(0.2354)\end{array}$ \\
\hline 1260.2 & $\begin{array}{c}0.3687 \\
(0.1672)\end{array}$ & $\begin{array}{c}0.3826 \\
(0.1766)\end{array}$ & $\begin{array}{c}0.4154 \\
(0.2008)\end{array}$ & $\begin{array}{c}0.4726 \\
(0.2683)\end{array}$ & $\begin{array}{c}0.4985 \\
(0.2891)\end{array}$ \\
\hline 1371.3 & $\begin{array}{c}- \\
(0.2008)\end{array}$ & $\begin{array}{c}- \\
(0.2129)\end{array}$ & $\begin{array}{c}- \\
(0.2406)\end{array}$ & $\begin{array}{c}- \\
(0.3098)\end{array}$ & $\begin{array}{c}- \\
(0.3358)\end{array}$ \\
\hline 1538.0 & $\begin{array}{c}- \\
(0.2666)\end{array}$ & $\begin{array}{c}- \\
(0.2804)\end{array}$ & $\begin{array}{c}- \\
(0.3116)\end{array}$ & $\begin{array}{c}- \\
(0.3843)\end{array}$ & $\begin{array}{c}- \\
(0.4189)\end{array}$ \\
\hline 1649.1 & $\begin{array}{c}- \\
(0.3289) \\
\end{array}$ & $\begin{array}{c}- \\
(0.3393) \\
\end{array}$ & $\begin{array}{c}- \\
(0.3791)\end{array}$ & $\begin{array}{c}- \\
(0.4535) \\
\end{array}$ & $\begin{array}{c}- \\
(0.5020)\end{array}$ \\
\hline
\end{tabular}

Table 5. Material properties of SIP

Table 6. Conductivity of LI-900 tile $\left(\mathrm{W} / \mathrm{m}-{ }^{\circ} \mathrm{C}\right)$ with respect to temperature and pressure 


\begin{tabular}{||c||c||c||}
\hline $\begin{array}{c}\mathbf{T} \\
\left({ }^{\circ} \mathbf{C}\right)\end{array}$ & $\begin{array}{c}\mathbf{C} \\
\left(\mathbf{J} / \mathbf{k g}^{\circ} \mathbf{C}\right)\end{array}$ & $\begin{array}{c}\boldsymbol{\alpha} \\
\left(\mathbf{1 0}^{\mathbf{6}} /{ }^{\circ} \mathbf{C}\right)\end{array}$ \\
\hline \hline-17.6 & 628.0 & 0.405 \\
\hline 121.3 & 879.2 & 0.540 \\
\hline 260.2 & 1055.1 & 0.648 \\
\hline 399.1 & 1151.4 & 0.720 \\
\hline 538.0 & 1205.8 & 0.792 \\
\hline 676.9 & 1239.3 & 0.576 \\
\hline 815.7 & 1256.0 & 0.480 \\
\hline 926.9 & 1264.4 & 0.432 \\
\hline 954.6 & 1268.6 & - \\
\hline 1093.5 & - & 0.360 \\
\hline
\end{tabular}

$\begin{array}{llll}\boldsymbol{\rho} & =194 & \mathrm{~kg} / \mathrm{m}^{3} \\ \mathbf{E}_{\mathrm{x}}, \mathbf{E}_{\mathrm{z}} & =172.4 \mathrm{MPa} \\ \mathbf{E}_{\mathrm{y}} & =48.3 \mathrm{MPa} \\ \mathbf{G}_{\mathrm{xy}}, \mathbf{G}_{\mathrm{yz}} & =20.7 & \mathrm{MPa} \\ \mathbf{G}_{\mathrm{xz}} & =72.4 & \mathrm{MPa} \\ \boldsymbol{v}_{\mathrm{xy}} & =0.16 & \\ \boldsymbol{v}_{\mathrm{xz}} & =0.18 \\ \boldsymbol{v}_{\mathrm{yz}} & =0.04 & \end{array}$

Table 7. Material properties of LI-900 tiles

\begin{tabular}{|c|c|c|c|c|c|c|c|}
\hline $\begin{array}{c}\text { TPS } \\
\text { component }\end{array}$ & $\begin{array}{c}D \\
\text { (inch) }\end{array}$ & \multicolumn{2}{|c|}{$\begin{array}{c}\text { Temperature } \\
\left({ }^{\circ} \mathrm{C}\right)\end{array}$} & \multicolumn{2}{|c|}{ \% change } & \multicolumn{2}{|c|}{$\begin{array}{c}\text { Time } \\
\text { (s) }\end{array}$} \\
\hline \multirow{4}{*}{ Tile } & 0 & \multicolumn{2}{|c|}{981} & \multicolumn{2}{|c|}{ NA } & \multicolumn{2}{|c|}{850} \\
\hline & 0.5 & 1703 & 1940 & 73.6 & 97.8 & 850 & 850 \\
\hline & 1.0 & 1898 & 2171 & 93.5 & 121.3 & 850 & 850 \\
\hline & 1.5 & 2080 & 2313 & 112.0 & 135.8 & 850 & 850 \\
\hline \multirow{4}{*}{ SIP } & 0 & \multicolumn{2}{|c|}{150} & \multicolumn{2}{|c|}{ NA } & \multicolumn{2}{|c|}{5000} \\
\hline & 0.5 & 153 & 160 & 2.0 & 6.7 & 4950 & 4950 \\
\hline & 1.0 & 173 & 206 & 15.3 & 37.3 & 4850 & 4700 \\
\hline & 1.5 & 215 & 302 & 43.3 & 101.3 & 4450 & 4150 \\
\hline \multirow{4}{*}{$\begin{array}{l}\text { Underlying } \\
\text { structure }\end{array}$} & 0 & \multicolumn{2}{|c|}{150} & \multicolumn{2}{|c|}{ NA } & \multicolumn{2}{|c|}{5450} \\
\hline & 0.5 & 153 & 159 & 2.0 & 6.0 & 5400 & 5450 \\
\hline & 1.0 & 172 & 205 & 14.7 & 36.7 & 5250 & 5100 \\
\hline & 1.5 & 213 & 300 & 42.0 & 100.0 & 4900 & 4500 \\
\hline
\end{tabular}

CFL3D - bold, EP - italics

Table 8. Maximum temperatures results for all TPS components subjected to flow dependent heat loads

\begin{tabular}{|c|c|c|c|c|c|c|c|}
\hline $\begin{array}{c}\text { TPS } \\
\text { component } \\
\end{array}$ & $\begin{array}{c}D \\
\text { (inch) }\end{array}$ & \multicolumn{2}{|c|}{$\begin{array}{c}\text { Max. von Mises stress } \\
(\mathbf{k P a})\end{array}$} & \multicolumn{2}{|c|}{ \% change } & \multicolumn{2}{|c|}{$\begin{array}{c}\text { Time } \\
\text { (s) }\end{array}$} \\
\hline \multirow{4}{*}{ Tile } & 0 & \multicolumn{2}{|c|}{65.0} & \multicolumn{2}{|c|}{ NA } & \multicolumn{2}{|c|}{200} \\
\hline & 0.5 & 99.8 & 87.9 & 53.5 & 35.2 & 150 & 150 \\
\hline & 1.0 & 88.2 & 84.4 & 35.7 & 29.8 & 150 & 400 \\
\hline & 1.5 & 79.9 & 100.4 & 22.9 & 54.5 & 250 & 500 \\
\hline \multirow{4}{*}{ SIP } & 0 & \multicolumn{2}{|c|}{172} & \multicolumn{2}{|c|}{ NA } & \multicolumn{2}{|c|}{5450} \\
\hline & 0.5 & 178 & 185 & 3.5 & 7.6 & 5400 & 5350 \\
\hline & 1.0 & 197 & 228 & 14.5 & 32.6 & 5250 & 5050 \\
\hline & 1.5 & 232 & 284 & 34.9 & 65.1 & 4900 & 4500 \\
\hline \multirow{4}{*}{$\begin{array}{l}\text { Underlying } \\
\text { structure }\end{array}$} & 0 & \multicolumn{2}{|c|}{470,000} & \multicolumn{2}{|c|}{ NA } & \multicolumn{2}{|c|}{5450} \\
\hline & 0.5 & 493,000 & 514,000 & 4.9 & 9.4 & 5400 & 5400 \\
\hline & 1.0 & 556,000 & 649,000 & 18.3 & 38.1 & 5250 & 5100 \\
\hline & 1.5 & 665,000 & 834,000 & 41.5 & 77.4 & 4900 & 4500 \\
\hline
\end{tabular}

CFL3D - bold, EP - italics

Table 9. Maximum von Mises Stress for all TPS components subjected to flow dependent heat loads and BC2 boundary condition 


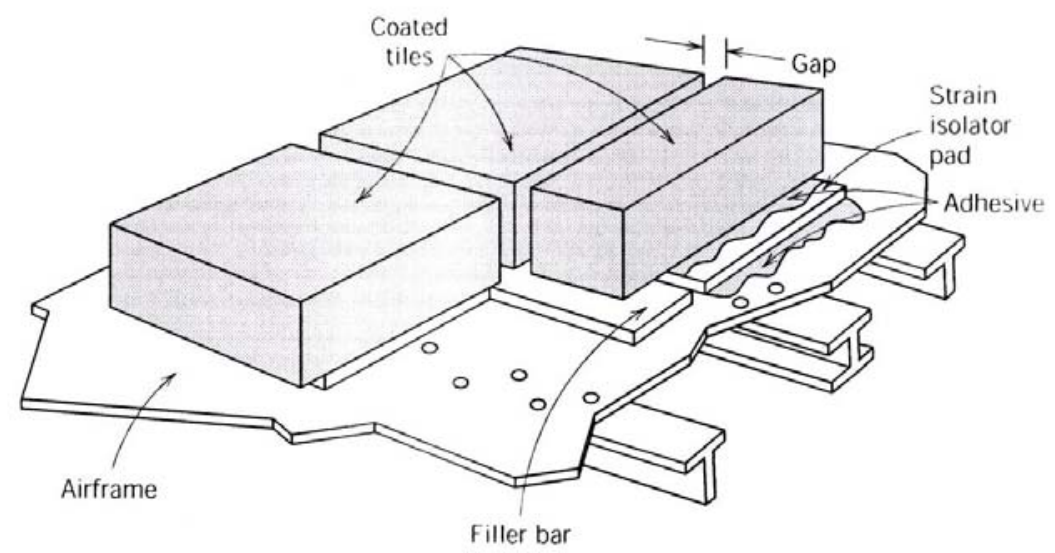

Figure 1. Space Shuttle TPS and Airframe (Callister, W.D., "Materials Science and Engineering: An introduction”, John Wiley and Sons Inc., New York, 2003, Pg. S-349)

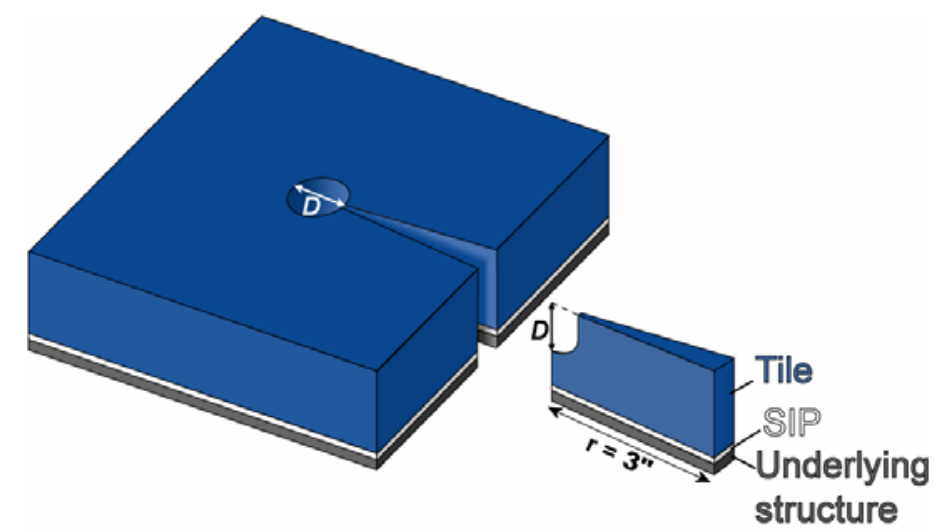

Figure 2. Schematic view of the discrete three-layered TPS model 


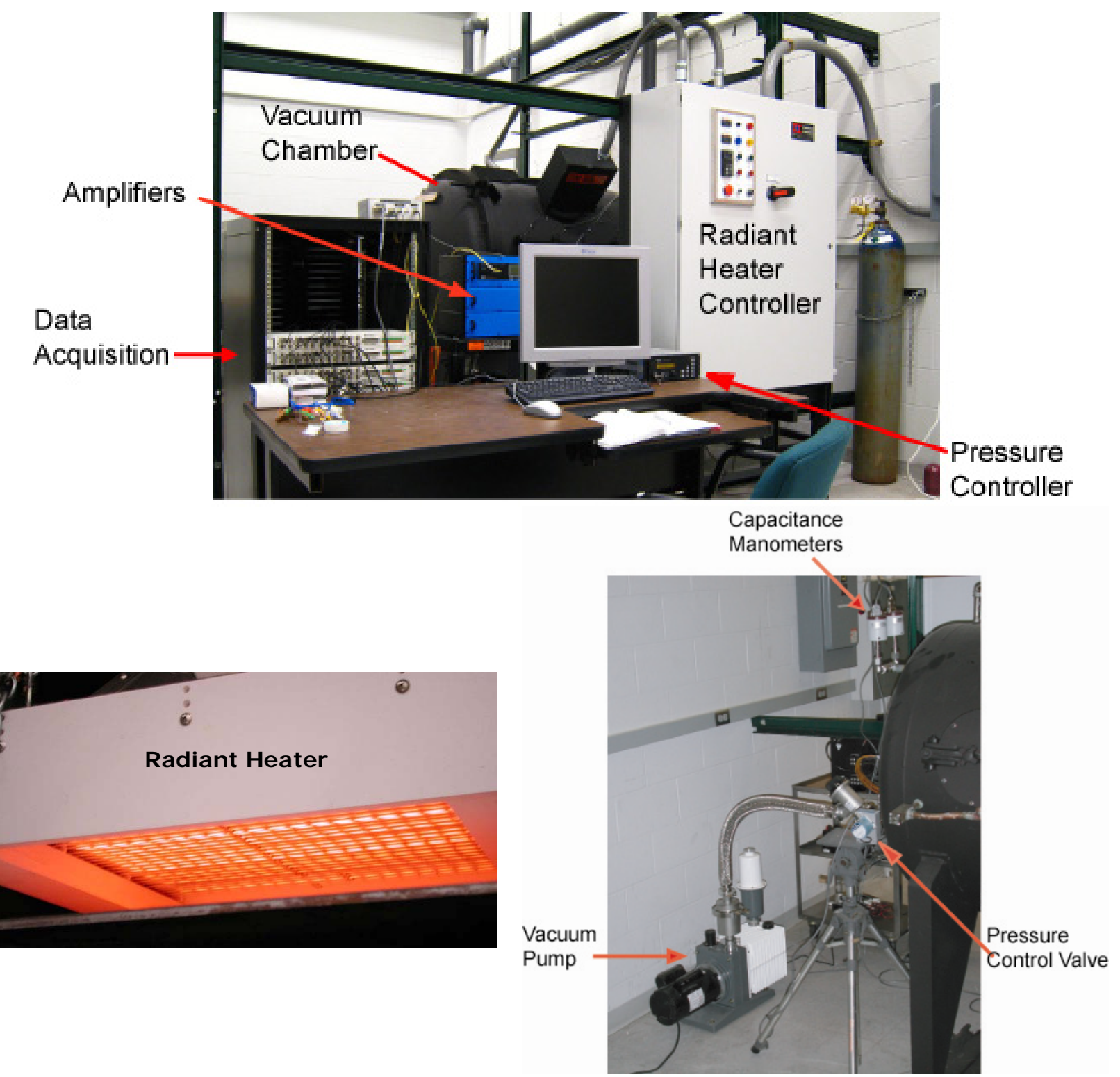

Figure 3. Overview of High Temperature Thermal Structures Testing Laboratory 


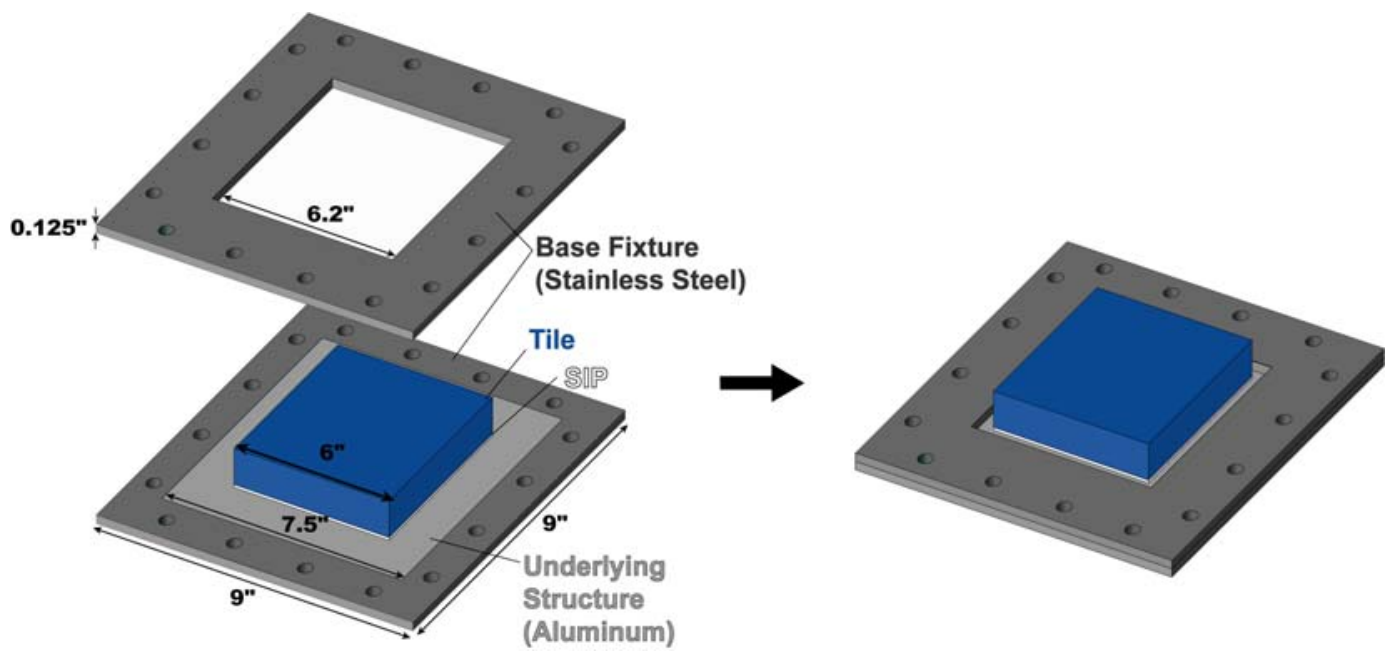

Figure 4. TPS specimen and load fixture
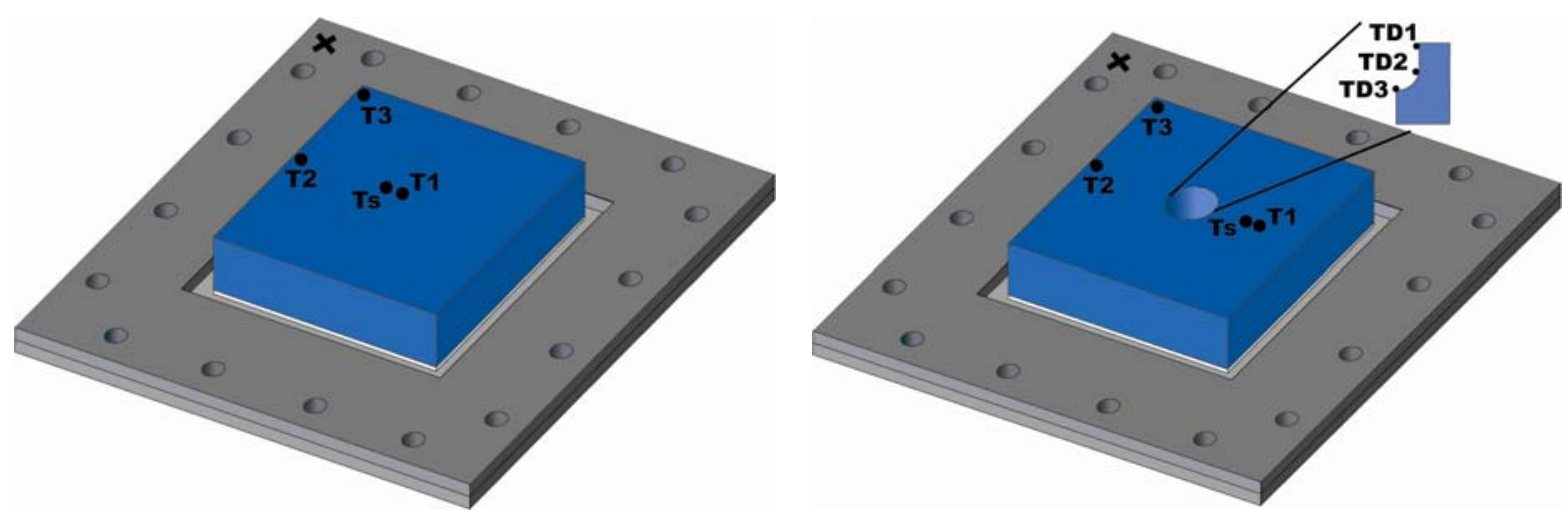

Top view

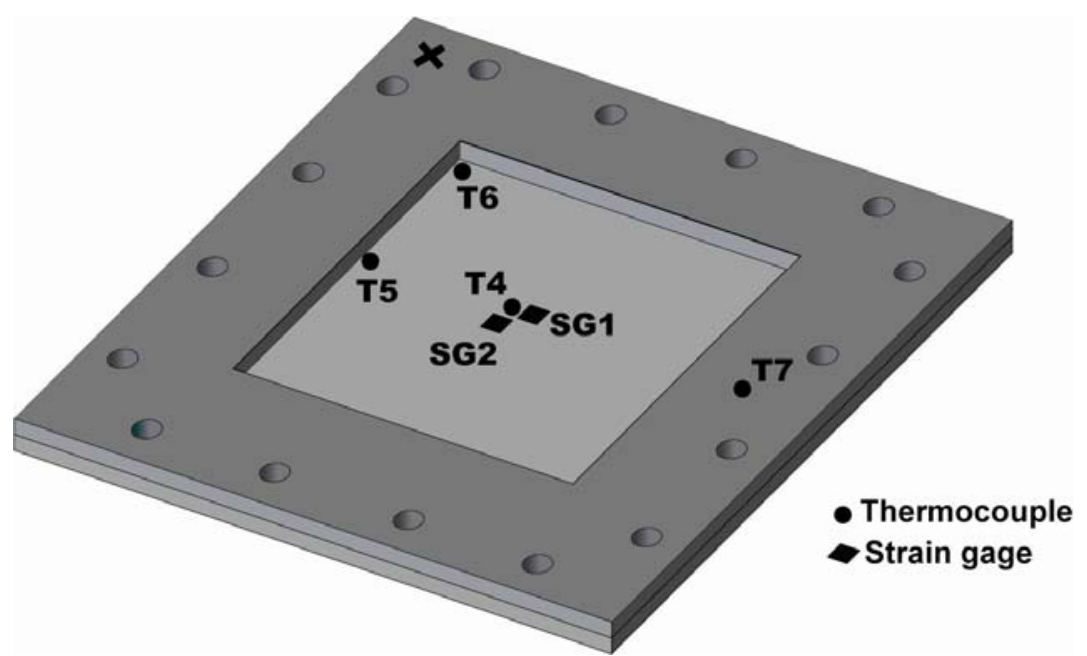

Bottom view

Figure 5. Location of thermocouples and strain gages on instrumented specimen 


\section{Heater}

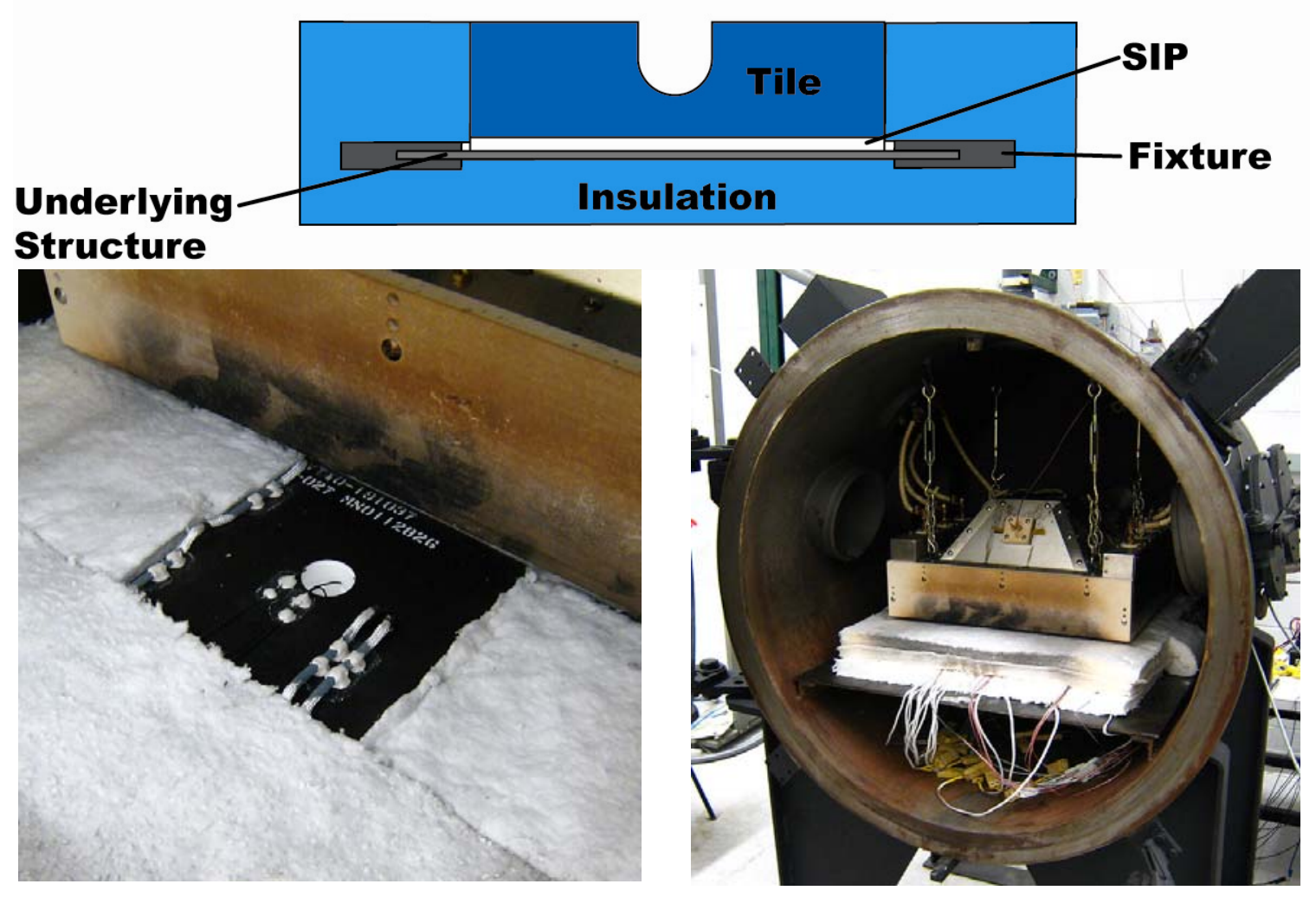

Figure 6. Illustration and Photographs of specimen assembly

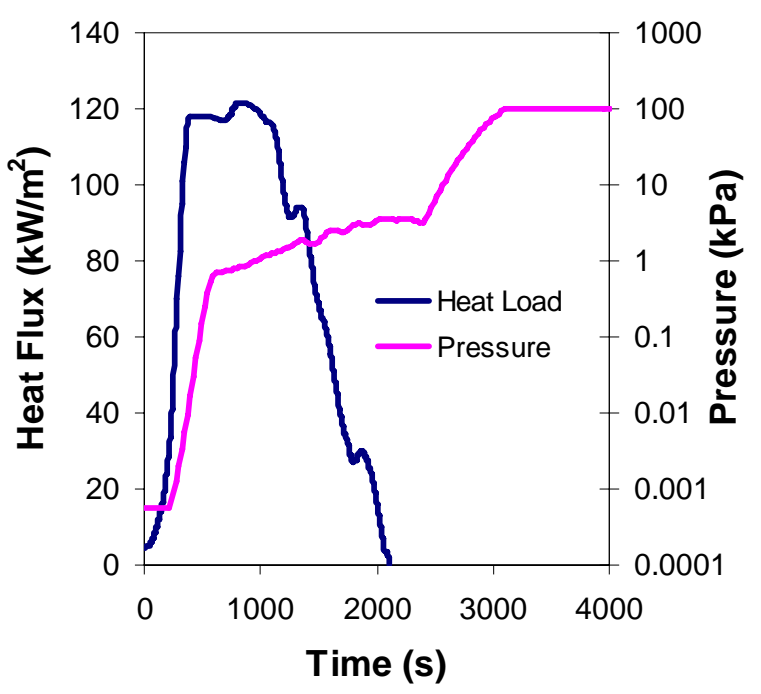

Figure 7. Re-entry heat load and pressure profile of ATS vehicel 

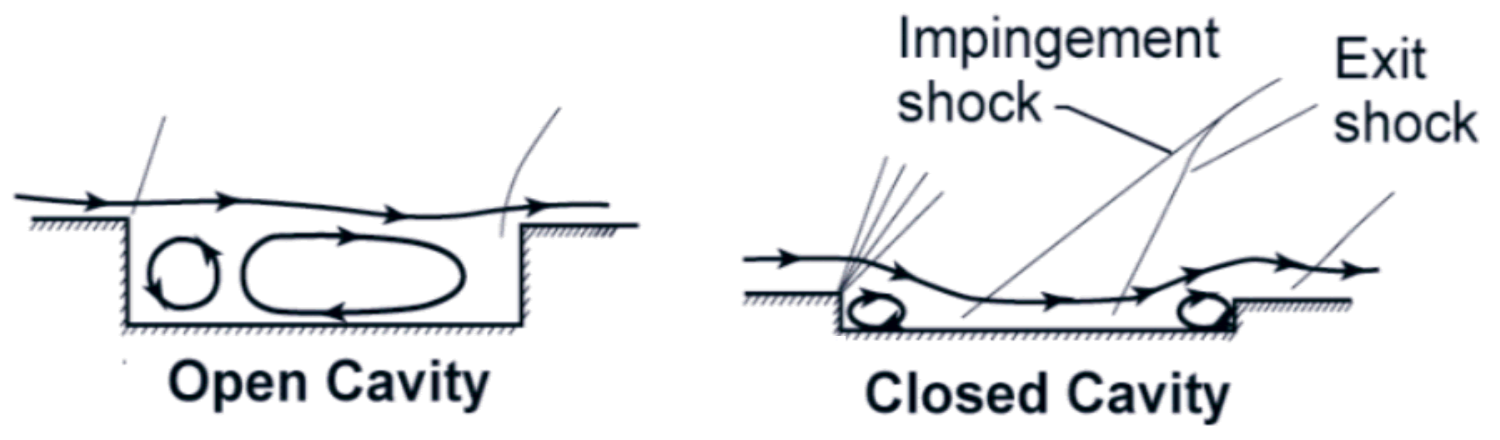

Figure 8. Different types of supersonic/hypersonic cavity flows.

\section{Flow Direction}
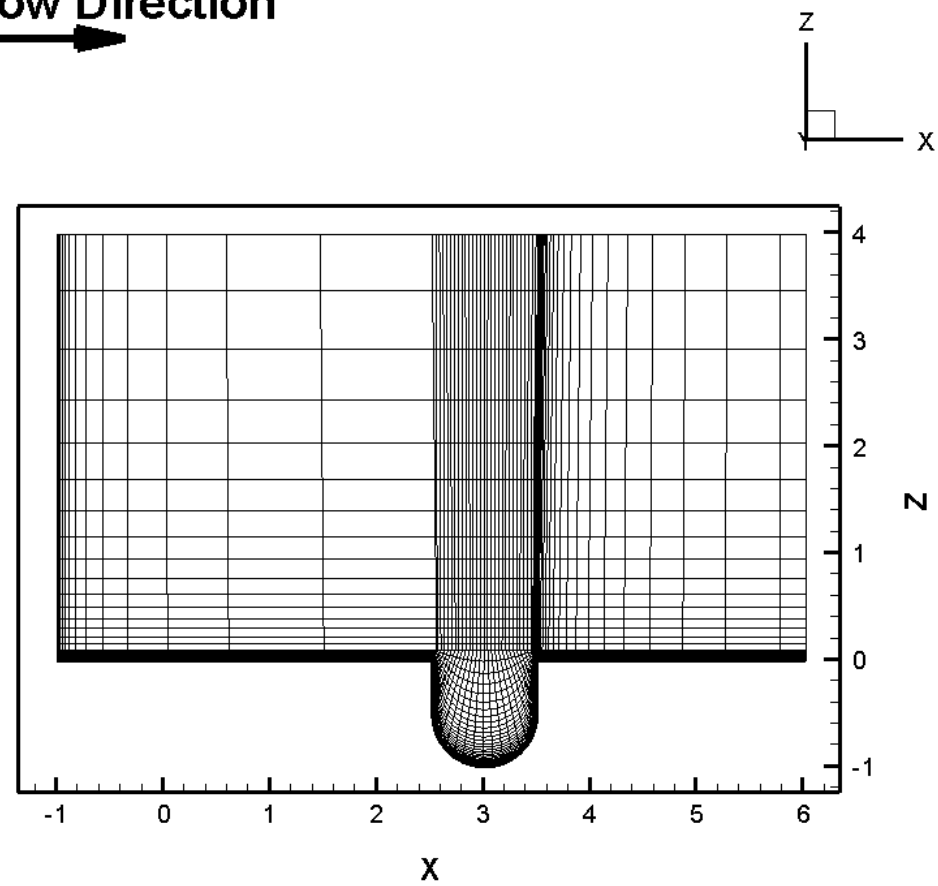

Figure 9. Coarsened view of CFL3D computational domain for the damaged tile. 


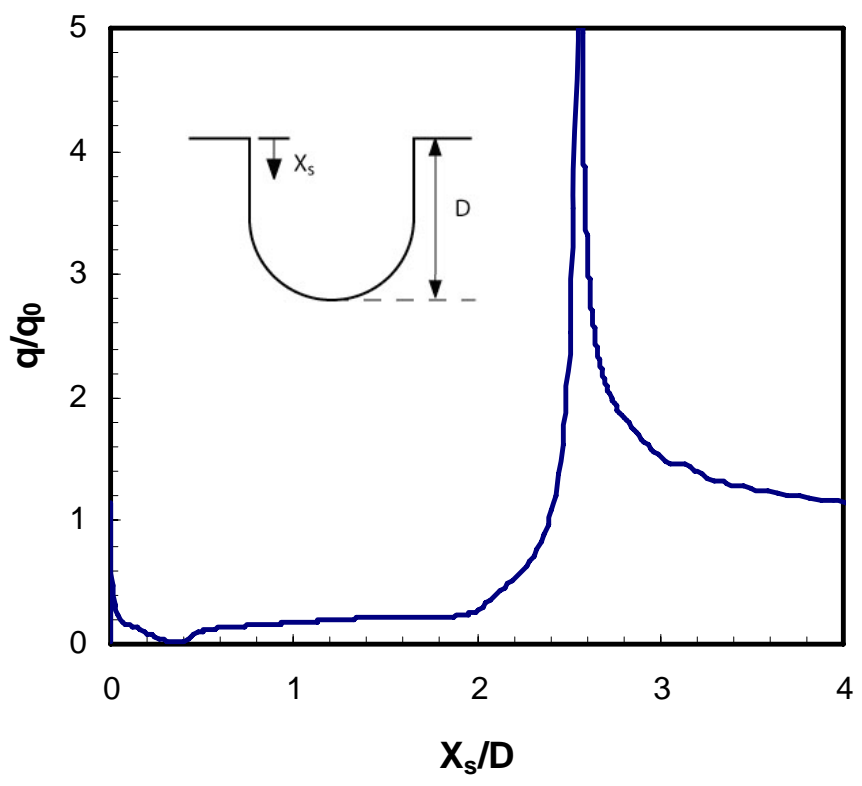

Figure 10. Heat load ratio along damaged surface from CFL3D analysis

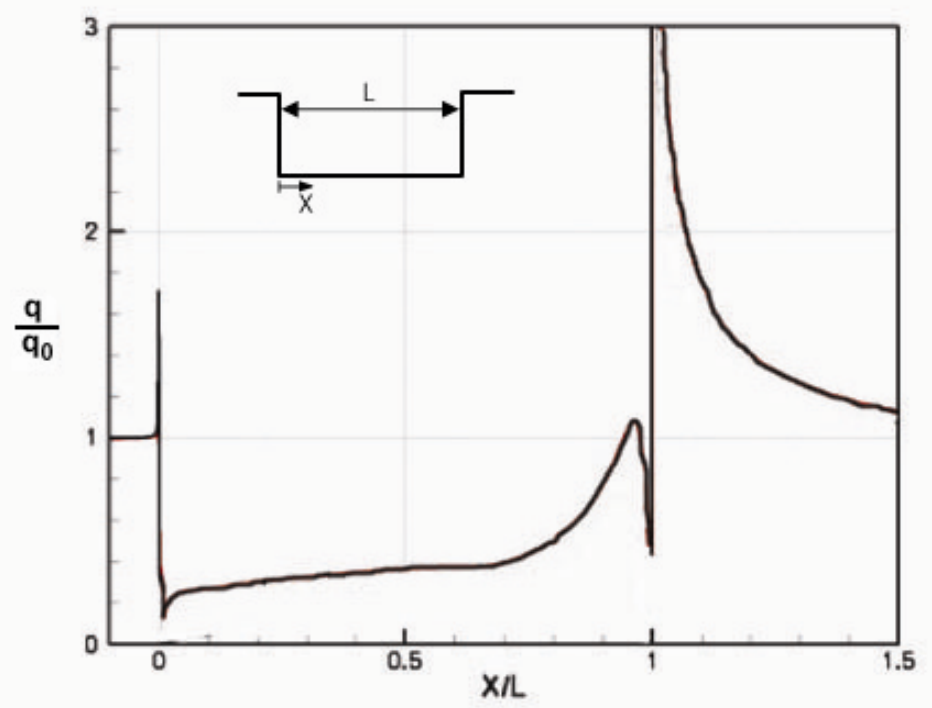

Figure 11. Heat load ratio profile from Ref. 21 


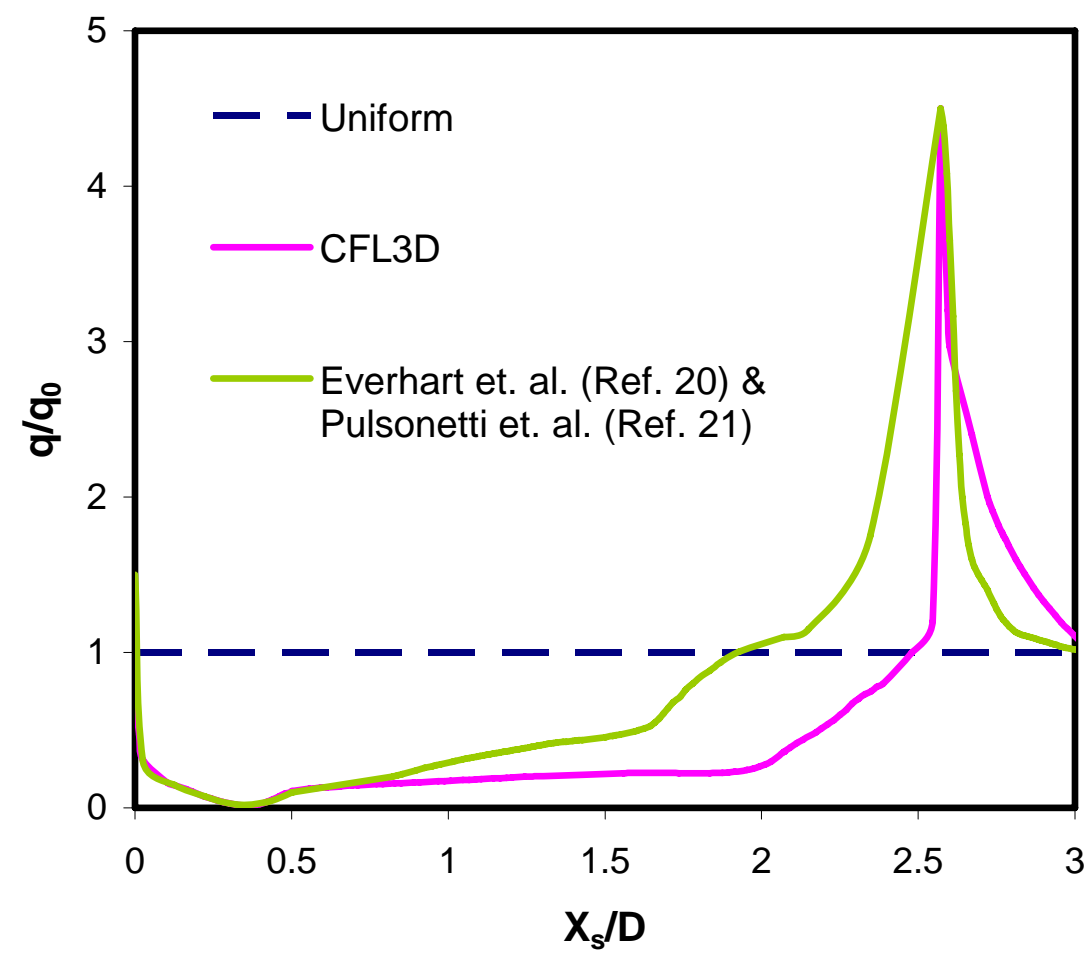

Figure 12. Heat load ratio profiles based on CFL3D and published data

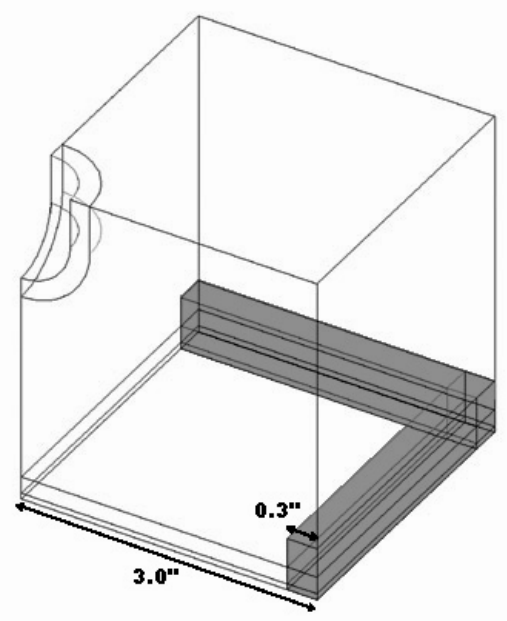

Figure 13. Quarter TPS model illustrating the boundary layer region for the thermal stress analysis 


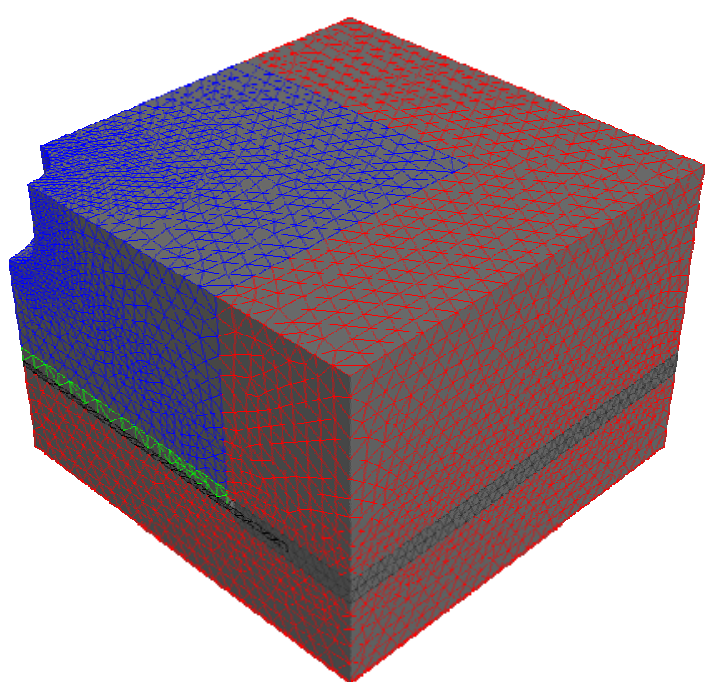

(a)

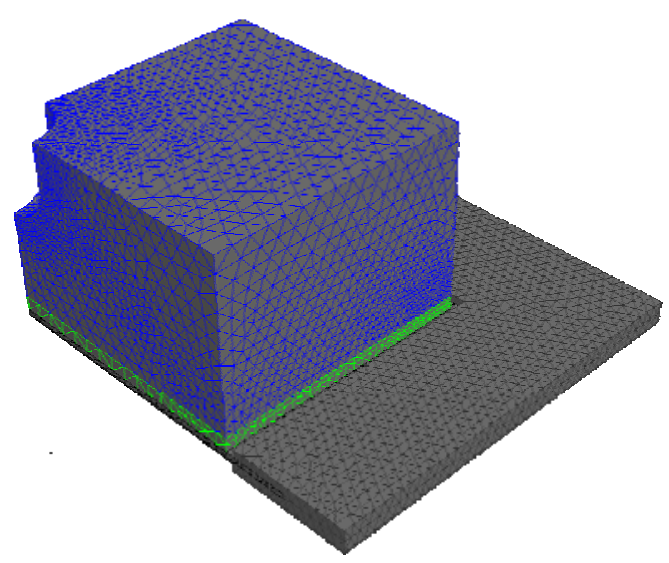

(b)

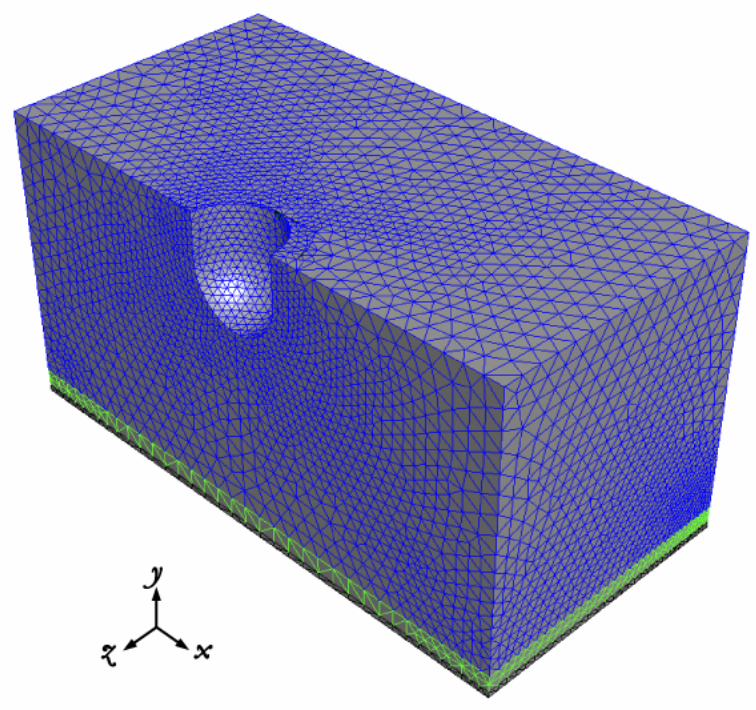

(c)

Figure 14. Schematic representation of FE meshes used

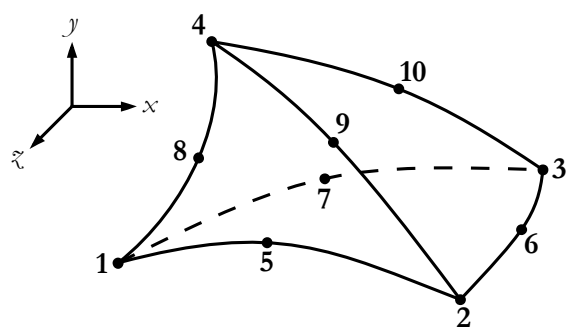

Figure 15. 10 node quadratic tetrahedron element 


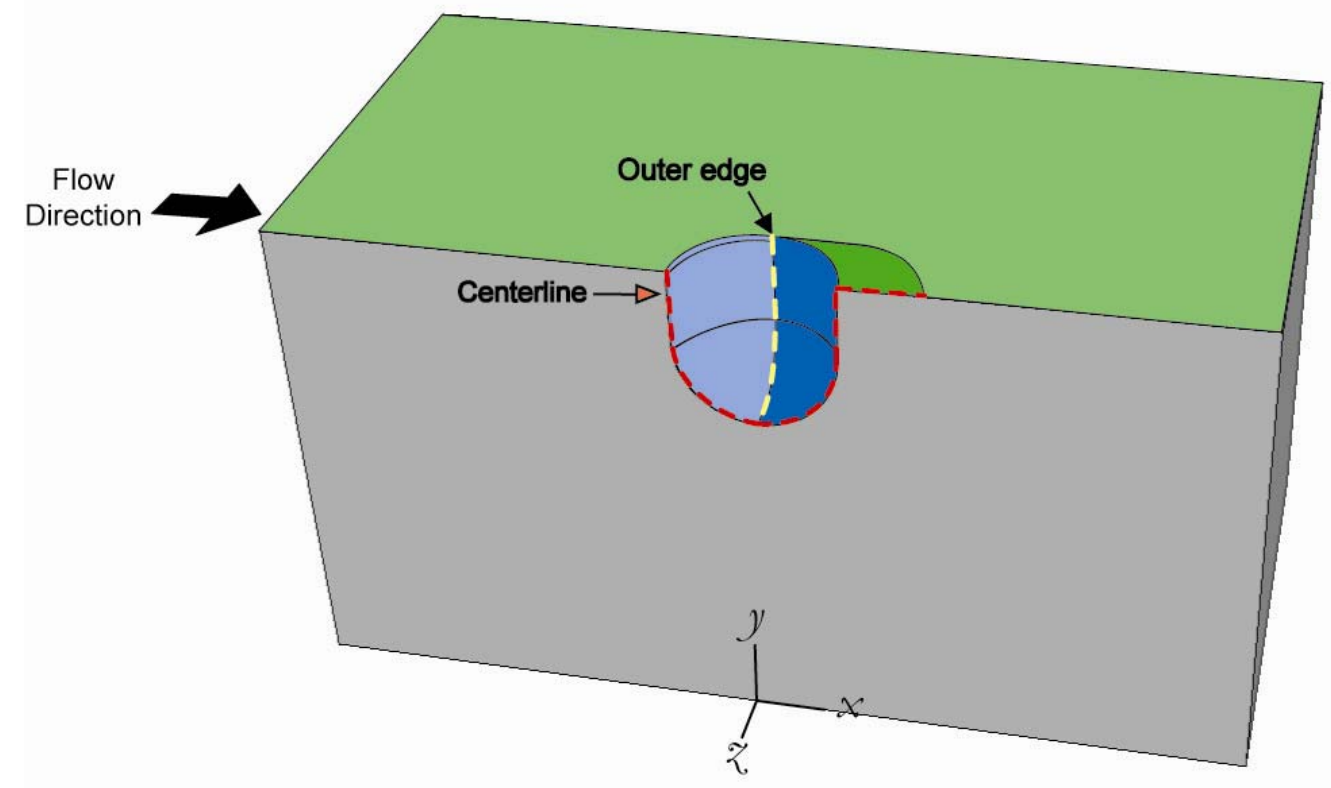

Figure 16. Half model of TPS showing the different sections required for the application of the flow dependent heat load
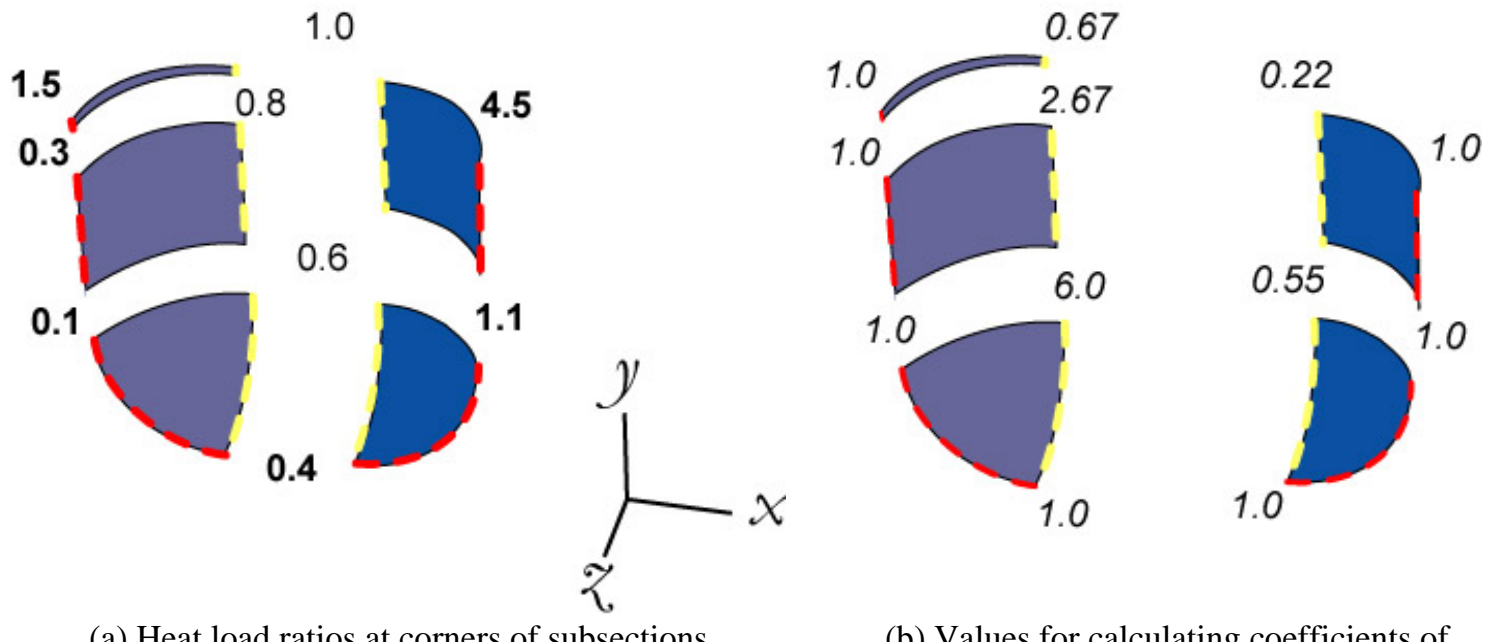

(a) Heat load ratios at corners of subsections

(b) Values for calculating coefficients of Equation (1)

Figure 17. Schematic of sub-sections of damaged surface. 


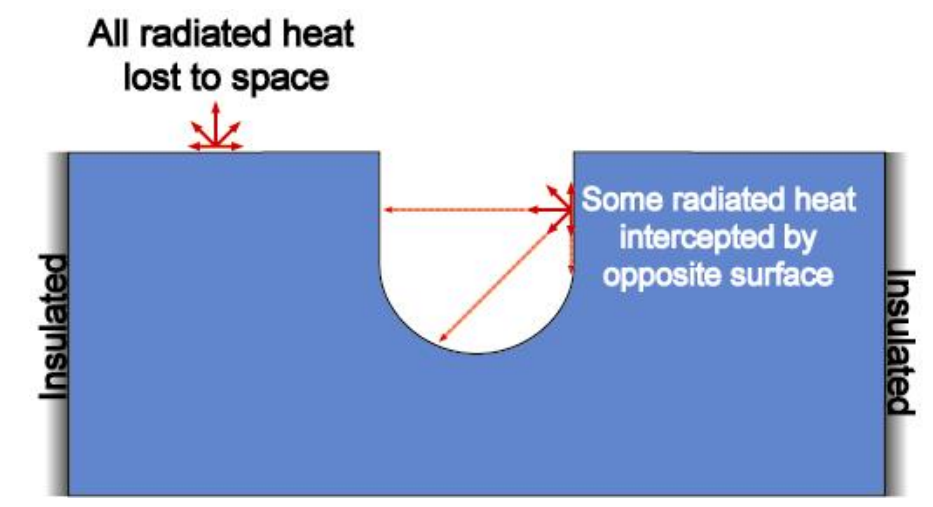

Figure 18. Schematic representation of radiation heat loss in the tile

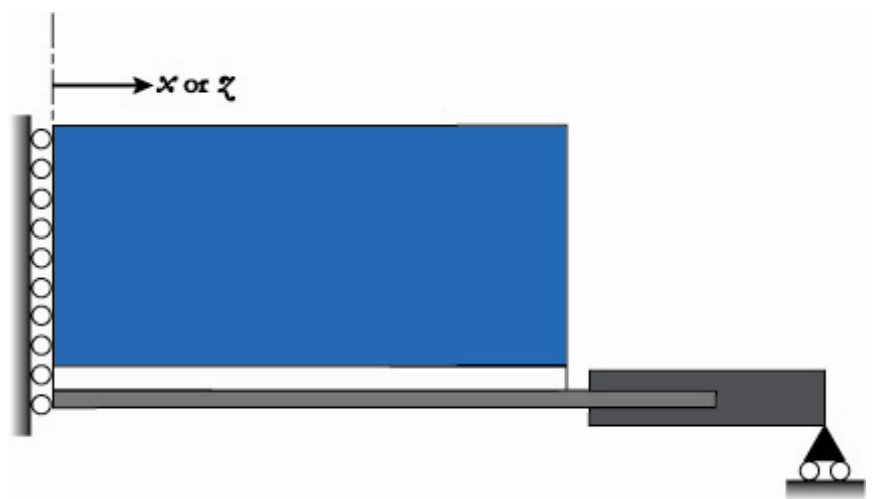

(a) unrestrained boundary condition, BC1

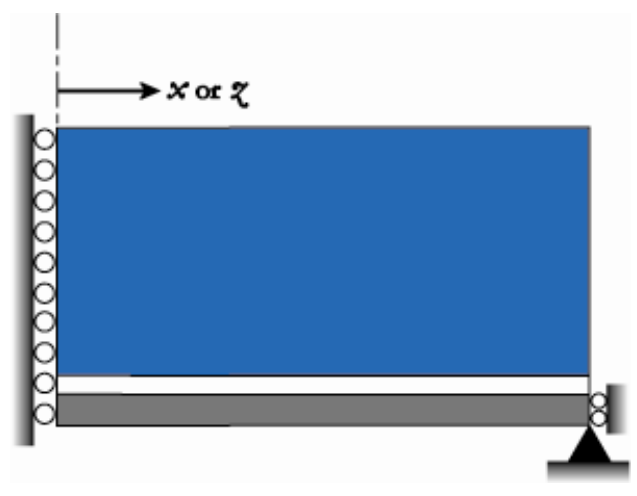

(b) restrained boundary condition, BC2

Figure 19. Structural boundary conditions applied to underlying structure

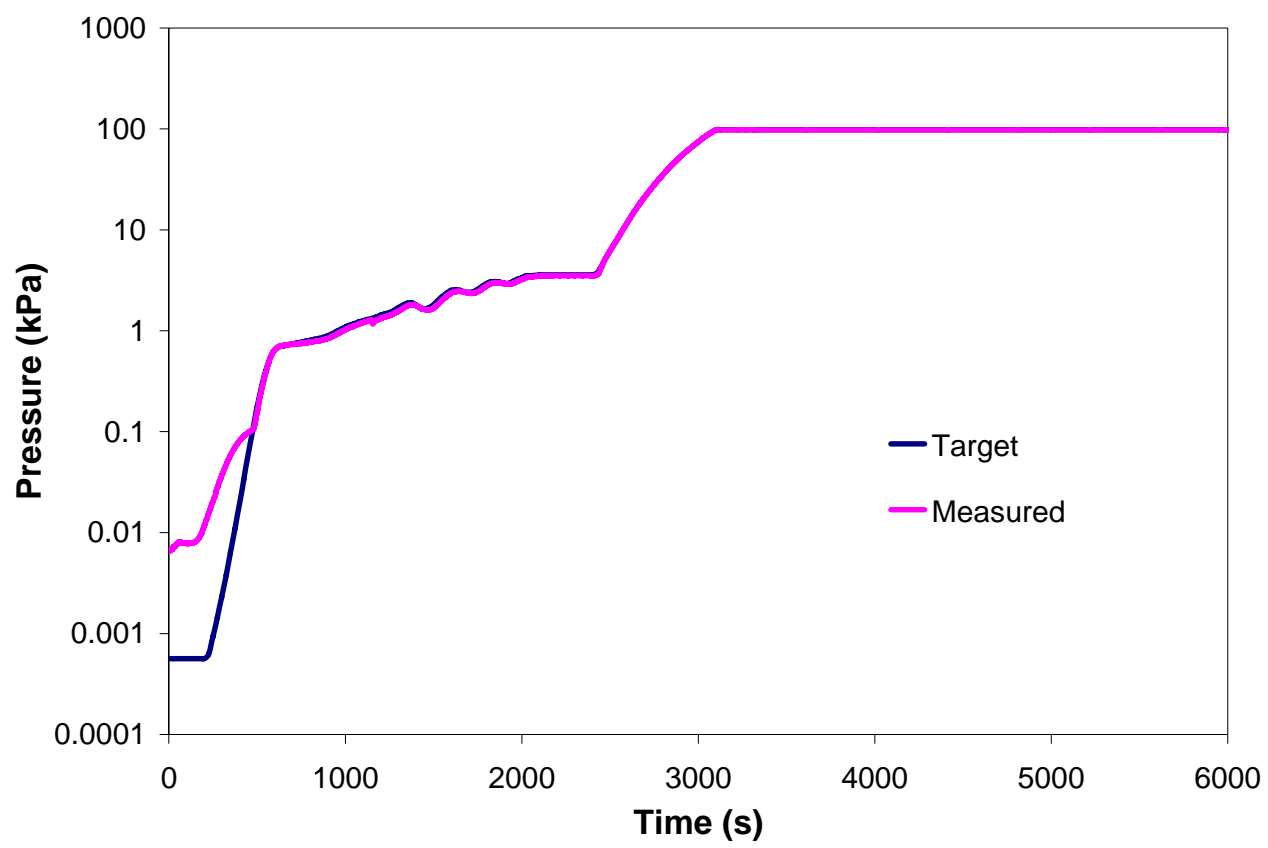

Figure 20. Comparison of target and measured re-entry pressure 


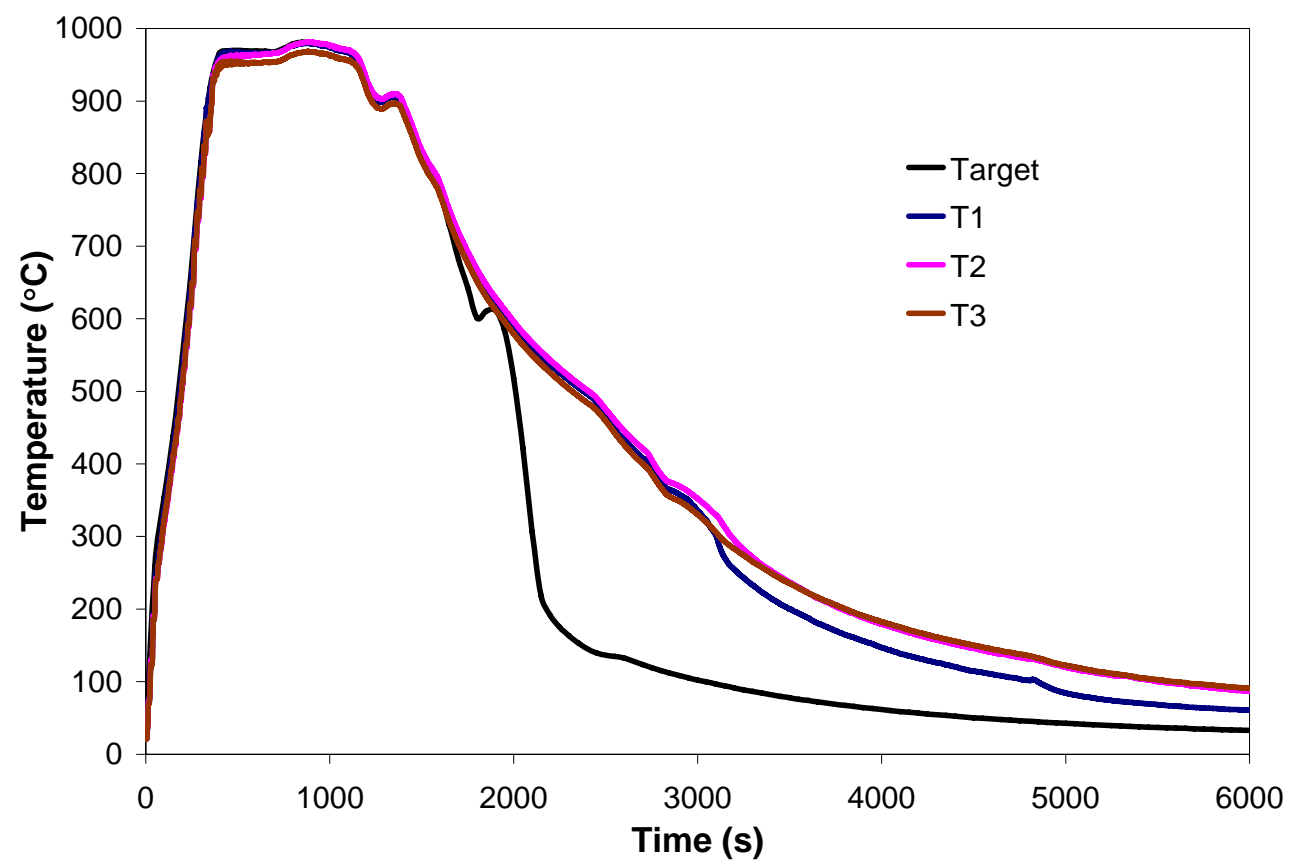

Figure 21. Comparison of target and measured surface temperature

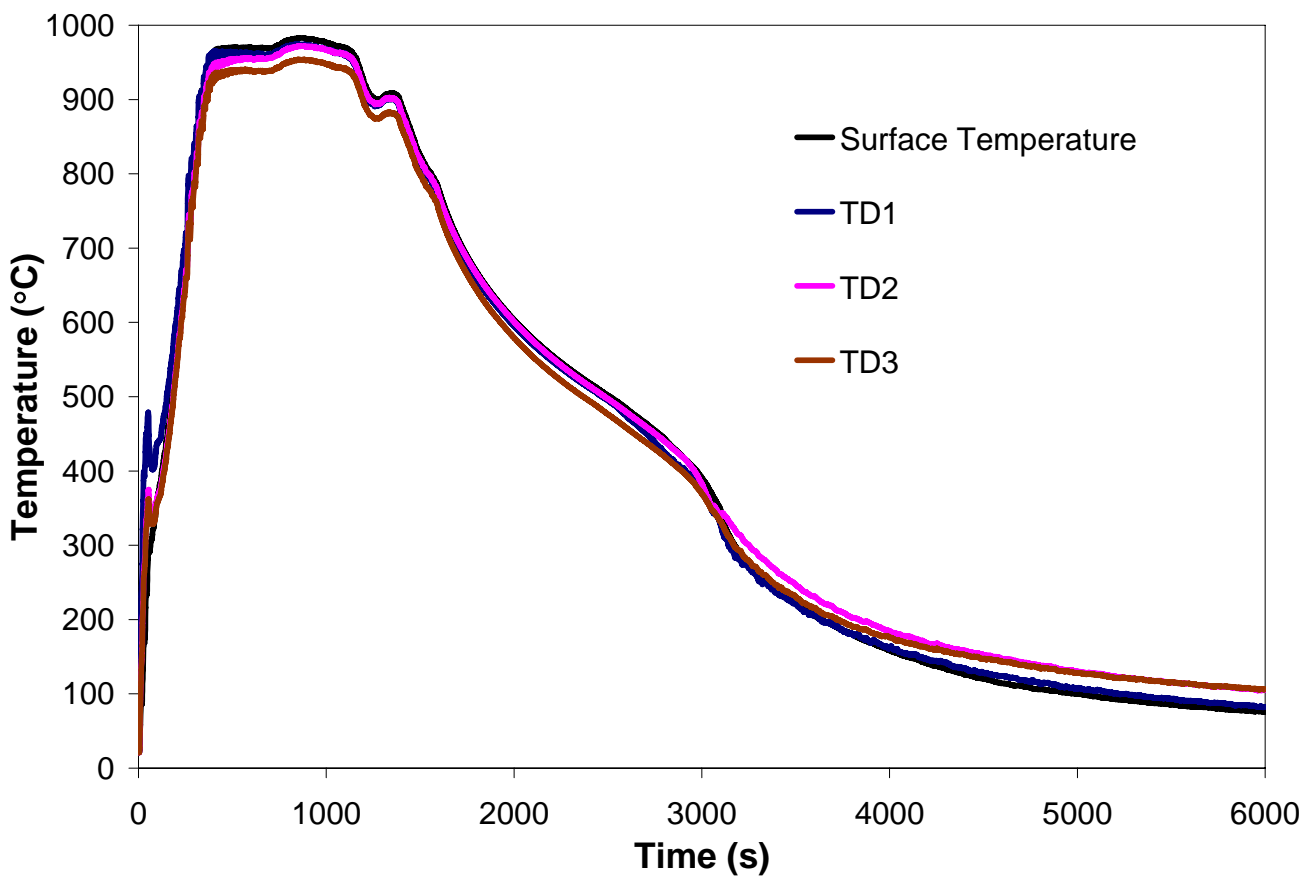

Figure 22. Comparison of temperatures on surface and in damaged region of specimen 


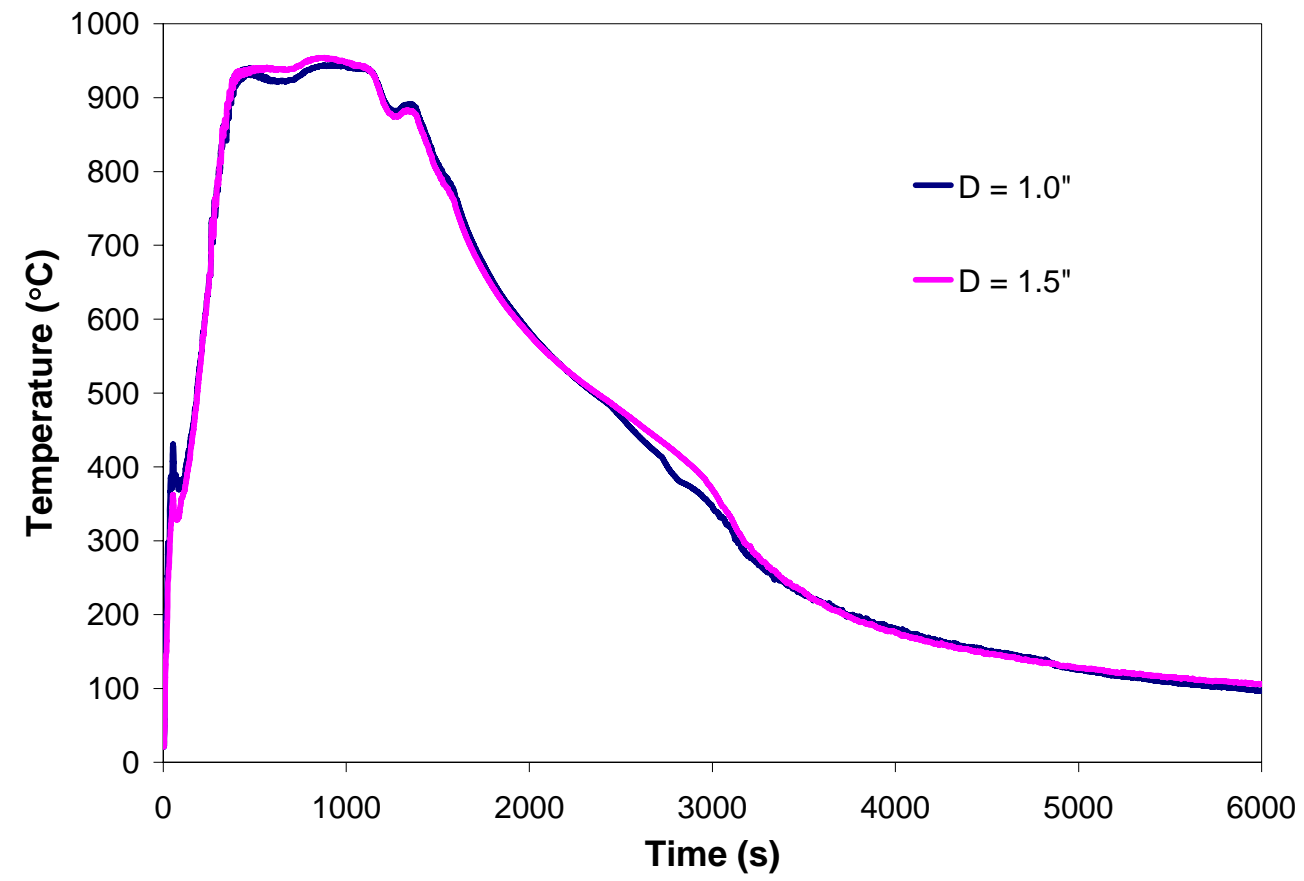

Figure 23. Comparison of temperatures at base of damaged region, TD3, between $D=1.0$ ” and 1.5" configuration

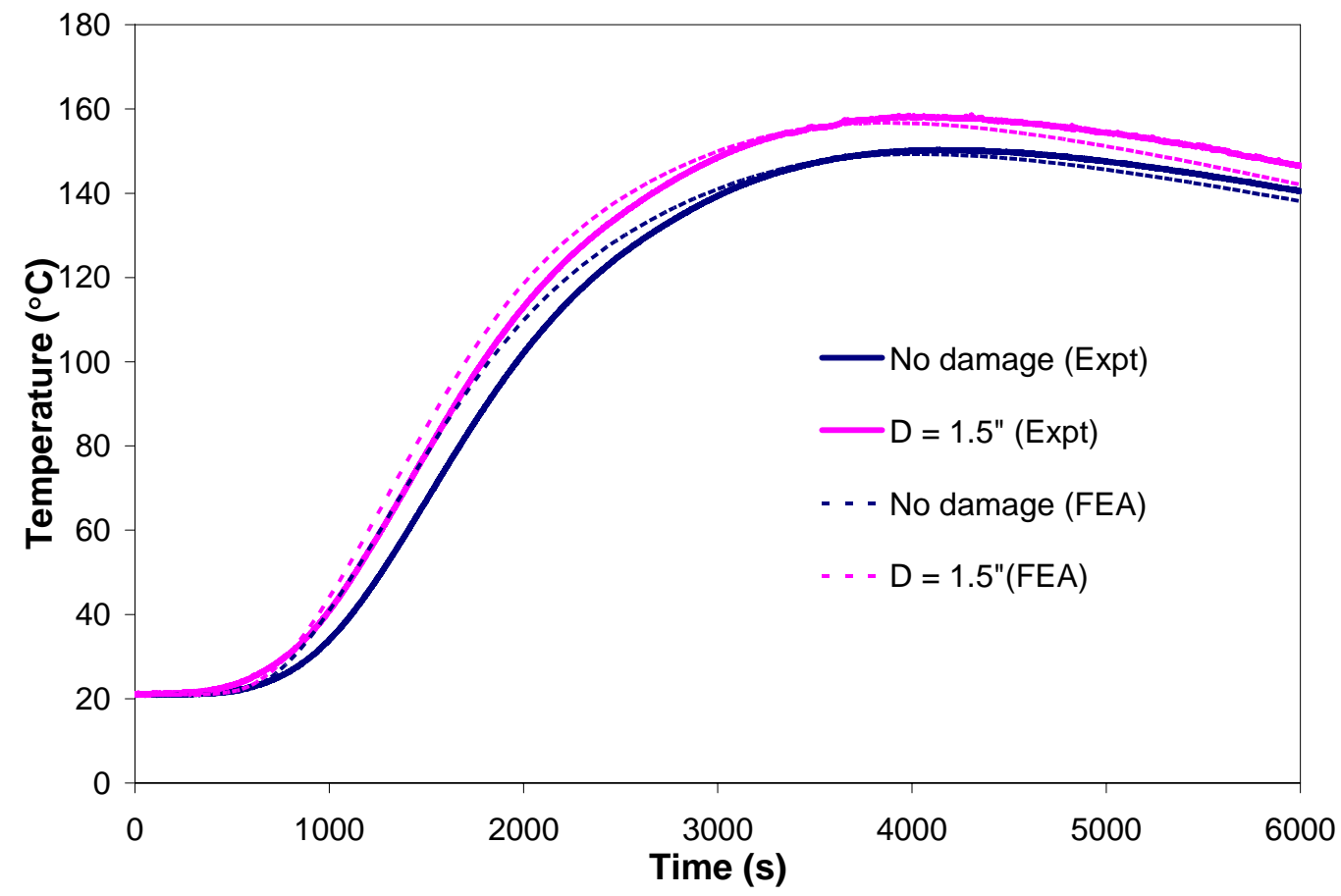

Figure 24. Comparison of predicted and measured temperatures for undamaged and $D=1.5$ ” configurations 


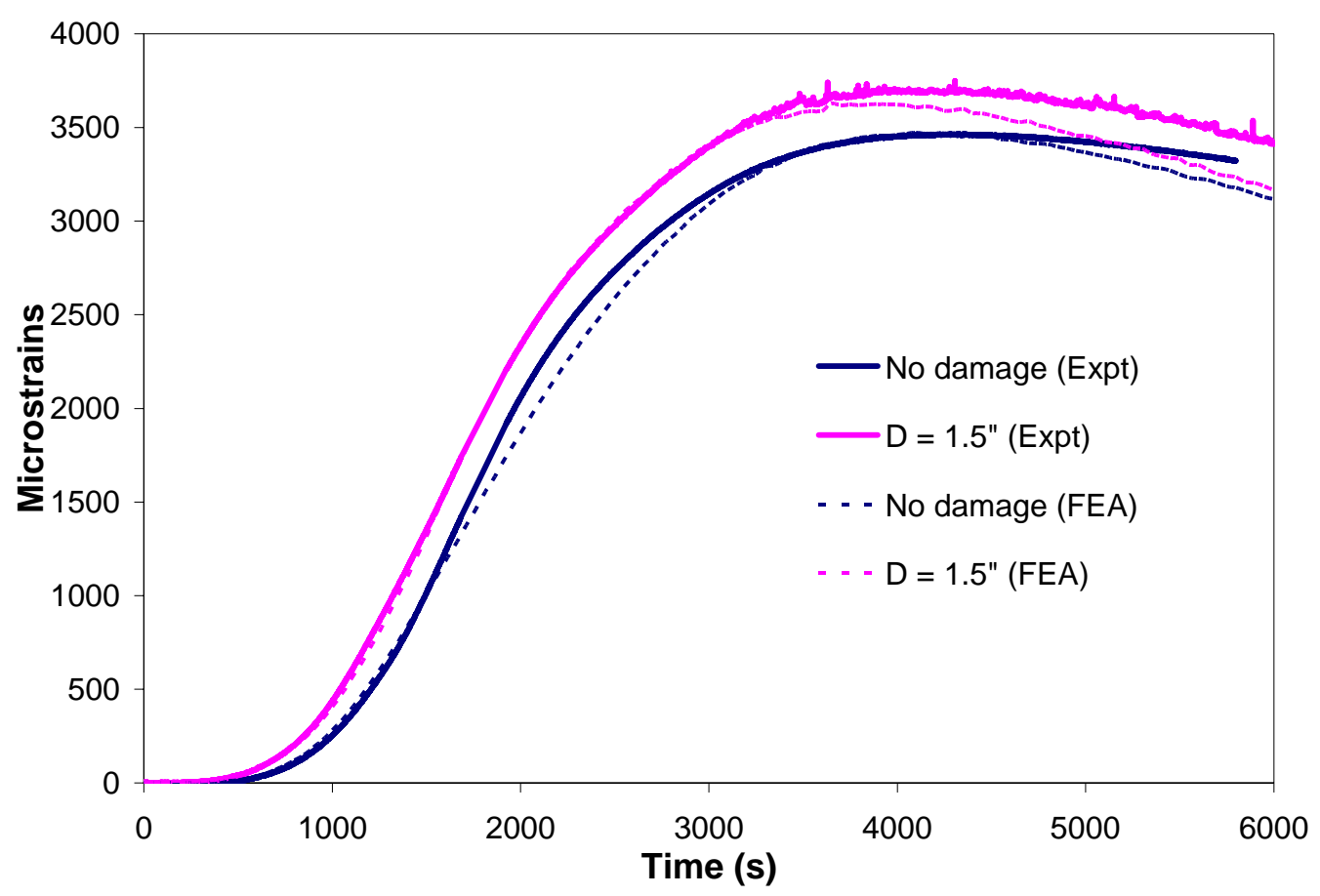

Figure 25. Comparison of predicted and measured strains for undamaged and $D=1.5$ ” configurations

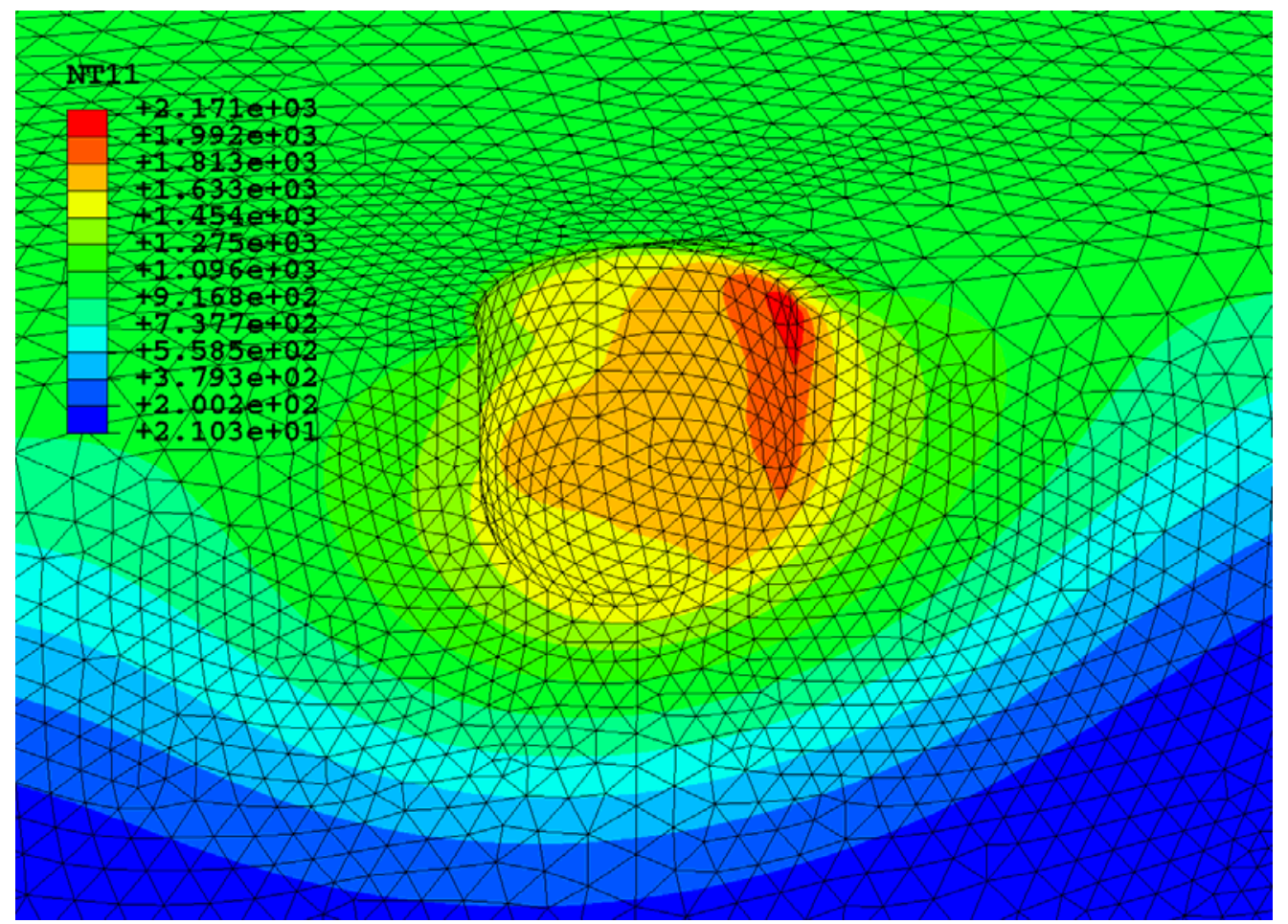

Figure 26. Temperature $\left({ }^{\circ} \mathrm{C}\right)$ contour plot of $D=1.0$ ” configuration subjected to EP heat load when maximum temperature is reached 